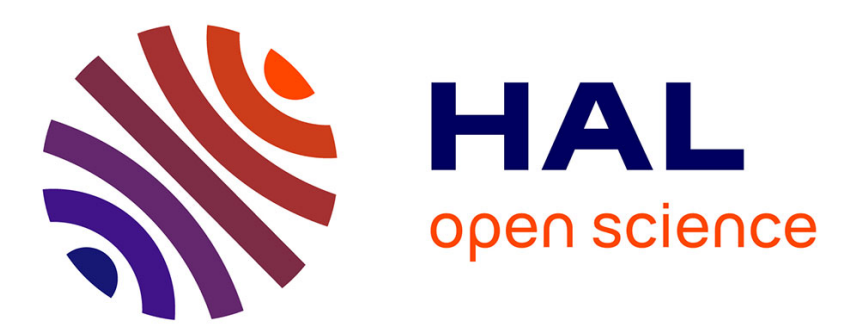

\title{
Beneficial Actions of Oleanolic Acid in an Experimental Model of Multiple Sclerosis: a Potential Therapeutic Role
}

Rubén Martín, Juliana Carvalho-Tavares, Marita Hernández, Mercedes Arnes, Valentina Ruiz-Gutierrez, María Luisa Nieto

\section{To cite this version:}

Rubén Martín, Juliana Carvalho-Tavares, Marita Hernández, Mercedes Arnes, Valentina RuizGutierrez, et al.. Beneficial Actions of Oleanolic Acid in an Experimental Model of Multiple Sclerosis: a Potential Therapeutic Role. Biochemical Pharmacology, 2009, 79 (2), pp.198. 10.1016/j.bcp.2009.08.002 . hal-00535822

\section{HAL Id: hal-00535822 \\ https://hal.science/hal-00535822}

Submitted on 13 Nov 2010

HAL is a multi-disciplinary open access archive for the deposit and dissemination of scientific research documents, whether they are published or not. The documents may come from teaching and research institutions in France or abroad, or from public or private research centers.
L'archive ouverte pluridisciplinaire HAL, est destinée au dépôt et à la diffusion de documents scientifiques de niveau recherche, publiés ou non, émanant des établissements d'enseignement et de recherche français ou étrangers, des laboratoires publics ou privés. 


\section{Accepted Manuscript}

Title: Beneficial Actions of Oleanolic Acid in an Experimental Model of Multiple Sclerosis: a Potential Therapeutic Role

Authors: Rubén Martín, Juliana Carvalho-Tavares, Marita Hernández, Mercedes Arnes, Valentina Ruiz-Gutierrez, María Luisa Nieto

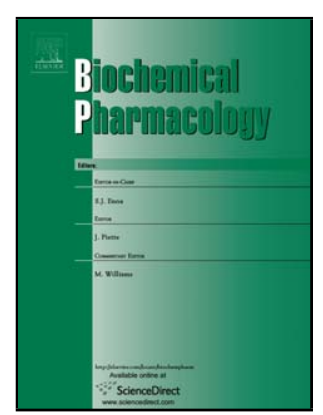

PII: S0006-2952(09)00681-9

DOI: doi:10.1016/j.bcp.2009.08.002

Reference: BCP 10285

To appear in: $\quad B C P$

Received date: $\quad$ 1-7-2009

Revised date: $\quad 31-7-2009$

Accepted date: $\quad$ 4-8-2009

Please cite this article as: Martín R, Carvalho-Tavares J, Hernández M, Arnes M, RuizGutierrez V, Nieto ML, Beneficial Actions of Oleanolic Acid in an Experimental Model of Multiple Sclerosis: a Potential Therapeutic Role, Biochemical Pharmacology (2008), doi:10.1016/j.bcp.2009.08.002

This is a PDF file of an unedited manuscript that has been accepted for publication. As a service to our customers we are providing this early version of the manuscript. The manuscript will undergo copyediting, typesetting, and review of the resulting proof before it is published in its final form. Please note that during the production process errors may be discovered which could affect the content, and all legal disclaimers that apply to the journal pertain. 


\title{
Beneficial Actions of Oleanolic Acid in an Experimental Model of Multiple Sclerosis: a Potential Therapeutic Role
}

\author{
Rubén Martín ${ }^{\mathrm{a}}$, Juliana Carvalho-Tavares ${ }^{\mathrm{a}}$, Marita Hernández ${ }^{\mathrm{a}}$, Mercedes Arnes ${ }^{\mathrm{a}}$, Valentina \\ Ruiz-Gutierrez ${ }^{\mathrm{b}}$ and María Luisa Nieto ${ }^{\mathrm{a} 1}$ \\ Instituto de Biología y Genética Molecular, CSIC-Universidad de Valladolid, Spain ${ }^{a}$ \\ Instituto de la Grasa de Sevilla, CSIC ${ }^{\mathrm{b}}$, Spain.
}

\section{Correspondence:}

Dr. M. L. Nieto, Instituto de Biología y Genética Molecular, C/Sanz y Forés s/n, 47003Valladolid, SPAIN. Telephone: +34-983-184836 FAX: +34-983-184800

e-mail: $\underline{\text { mlnieto@ibgm.uva.es }}$ 


\section{Abstract}

Multiple sclerosis (MS) is a chronic autoimmune inflammatory disease for which there exist no therapies without undesired side effects. Thus, the establishment of less toxic treatments is an ongoing challenge. Nowadays, research on medicinal plants has been attracting much attention, since screening of its active principles could prove useful in identification of safe and innovative pharmaceutical molecules. In this study we investigated the therapeutic effect of oleanolic acid (OA) a plant-derived triterpene with potent anti-inflammatory and immunomodulatory activities, whose actions on CNS diseases remain far from completely characterized. We focussed on the potential therapeutic effect of oleanolic acid (OA) on an accepted experimental model of MS, the experimental autoimmune encephalomyelitis (EAE). We have found that OA treatment, before or at the early onset of EAE, ameliorates neurological signs of EAE-mice. These beneficial effects of OA seem to be associated with a reduction of blood-brain barrier leakage and lower infiltration of inflammatory cells within the CNS, as well as with its modulatory role in Th1/Th2 polarization: inhibition of proinflammatory cytokines and chemokines, and stimulation of anti-inflammatory ones. Moreover, EAE-animals that were treated with OA had lower levels of anti-MOG antibodies than untreated EAE-mice.

Our findings show that the administration of the natural triterpenoid OA reduces and limits the severity and development of EAE. Therefore, OA therapy might be of clinical interest for human MS and other Th1 cell-mediated inflammatory diseases.

Keywords: Encephalomyelitis; Neuroimmunology; Inflammation; Pharmacology; Triterpenes. 


\section{Introduction}

Multiple sclerosis (MS) is an immuno-inflammatory, degenerative and often disabling disease of the central nervous system (CNS). The mechanisms by which this disease appears and progresses are heterogeneous in nature and still unclear, but studies of patients with MS suggest that the observed demyelination in the CNS is a result of a T-cell-mediated autoimmune response [1]. Unfortunately, MS is a frustrating disease because there is no definitive therapy. Conventional therapeutic strategies, including immunosuppressive drugs and steroids, present undesirable side effects, particularly in long-term treatment. It thus becomes necessary to establish less toxic therapeutic options.

Experimental allergic encephalomyelitis (EAE) is an experimental model widely used for the study of MS. The development and progression of clinical signs in EAE are associated with loss of blood-brain barrier (BBB) integrity and upregulation of adhesion molecules expression in CNS tissues, resulting in the migration of vascular inflammatory cells into the CNS compartment [2,3]. This inflammatory cascade triggers upregulation of various proinflammatory mediators produced by infiltrating leukocytes and resident glial cells in the CNS, which are determining factors in the tissue damage $[4,5]$.

In recent years, numerous studies describing the therapeutic properties of extracts from plants used in traditional medicine have been developed. Indeed, the use of such extracts as complementary and alternative medicine has lately increased, and also serves as an interesting source of drug candidates for the pharmaceutical industrial research. [6]. Oleanolic acid (OA), a natural pentacyclic triterpene widely found in a variety of plants, has been shown to display numerous biological properties with therapeutic potential $[7,8]$. It is present in the leaves and fruits of Olea europaea, among other vegetables. In fact, it is found in pomace olive oil, the principal source of fat in the Mediterranean diet [9] and supports the hypothesis that some components of olive oil may contribute to the beneficial properties of this diet for human 
health. It has been reported that OA has anti-inflammatory, anti-tumorigenic, anti-diabetic and

anti-viral properties, as well as cardioprotective, hepatoprotective and immunomodulatory effects [10-12]. Recently, a number of synthetic oleanane triterpenoid derivatives based on oleanolic acid has been synthesized, in an attempt to increase its potency; some of these are currently undergoing clinical trials for the treatment of solid tumors [13].

In addition, $\mathrm{OA}$ is clinically used in China for the treatment of hepatitis $\mathrm{B}$, and as an adjunct therapy for the prevention of hepatotoxicity [14]. In recent years, OA or herbal extracts containing OA have been demonstrated to present immunomodulatory actions [12] and promote improvement in brain function [15]. Synthetic analogs have also been revealed as novel neuroprotective agents [16]. However, no information regarding its in vivo effect on neuroinflammatory diseases is available. In this study, we demonstrate that OA significantly reduces the clinical signs of EAE when administrated both before and after onset of the disease. We outline its effects on inflammatory parameters such as cellular infiltration and BBB dysfunction, as well as on the expression levels of cytokines, chemokines and adhesion molecules. 


\section{Materials and Methods}

\subsection{Reagents}

CFA, Pertussis toxin, Evans Blue dye and all other chemicals not mentioned specifically were from Sigma-Aldrich (St Louis, MO, USA). Mac-1 (clone M1/70) and HRP-conjugated goat anti-mouse IgG1 and IgG2a polyclonal antibodies were from BD Pharmingen (San Jose, CA, USA). Goat anti-mouse IgG polyclonal antibody was from Amersham (Uppsala, Sweden). Ketamine was from Merial Laboratories (Barcelona, Spain) and Xylazine (Rompun) was from Bayer Healthcare (Monheim, Germany). ELISA Kits used for OPN were obtained from IBL (Hamburg, Germany); those for ICAM-1 were obtained from R\&D Systems (Abingdon, UK), and those for TNFa and IL-10 were gotten from Axxora Platform (Lausen, Switzerland). $\begin{array}{llll}\text { Myelin } & \text { oligodendrocyte } & \text { glycoprotein } & \text { (MOG) }\end{array}$ (MEVGWYRSPFSRVVHLYRNGK) was generated in the peptide synthesis laboratory of Dr F. Barahona (CBM, Madrid, Spain). Oleanolic acid (molecular formula: $\mathrm{C}_{30} \mathrm{H}_{48} \mathrm{O}_{3}$, molecular weight: 456.70) was obtained from pressed olive (Olea europaea) fruits as previously described [17] and was kindly provided in the powder form with a purity of $>98 \%$, by Dr. Ruiz-Gutierrez from the Instituto de la Grasa, Sevilla, Spain. The molecular structure of OA is shown in Fig 1.

\subsection{Active Induction of EAE}

C57BL/J6 mice (from Charles River Laboratories, Barcelona, Spain) were housed in the animal care facility at the Medical School of the University of Valladolid (UVa), Spain, and provided food and water ad lib. All experimental protocols were reviewed and approved by the Animal Ethics Committee of the UVa. 
Chronic progressive disease was induced in adult 8-10-wk-old female C57BL/J6 mice with myelin oligodendrocyte glycoprotein (MOG) ${ }_{35-55}$ peptide. Briefly, mice were injected in the tail base bilaterally with $100 \mu \mathrm{l}$ of an innoculum containing $100 \mu \mathrm{g}$ of MOG peptide $35-55$ emulsified in complete Freund's adjuvant (CFA) containing $0.4 \mathrm{mg}$ Mycobacterium tuberculosis (H37Ra; Difco, Detroit, MI, USA). MOG-sensitized animals received a dose of $300 \mathrm{ng}$ of Pertussis toxin intraperitoneal injection (i.p.) on the day of the immunization and two days later.

\subsection{OA Treatment Procedure.}

OA was first dissolved in 2\% w/v dimethyl sulfoxide (DMSO) and then diluted with PBS for each experiment (the final concentration of DMSO is $0.2 \%, \mathrm{w} / \mathrm{v}$ ). Mice were treated daily with $0.2 \% \mathrm{w} / \mathrm{v}$ DMSO or $50 \mathrm{mg} / \mathrm{kg} / \mathrm{d}$ OA by i.p. injection from day 7 (before the onset of EAE: semiprophylactic, OA2) or day 12 (after the onset of the symptoms: therapeutic, OA1) after immunization, until termination of the experiment: i) approximately 21-24 days postimmunization, when EAE mice showed hind limb paralysis, or ii), when severe symptoms of each animal group were apparent (tetraplegia), to assess the impact of oleanolic acid treatment on the evolution of disease. Control mice (without EAE induction) were also injected daily with OA for an equivalent period of time.

\subsection{Clinical Evaluation.}

Mice were examined, weighed and scored daily in a double-blind manner for signs of EAE for up to 20-24 days after immunization. The scores were graded according to the clinical severity of neurological symptoms on a scale of 0 to 5 , with 0.5 points for intermediate clinical findings: grade 0, no abnormality; grade 0.5, partial loss/reduced tail tone, assessed by inability to curl the distal end of the tail; grade 1, tail atony; grade 1.5, slightly/moderately clumsy gait, impaired righting ability, or combination; grade 2, hind limb weakness; grade 
2.5, partial hind limb paralysis; grade 3, complete hind limb paralysis; grade 3.5, complete hind limb paralysis and fore limb weakness; grade 4, tetraplegic; grade 5, moribund state or death. Scores of the two blinded investigators were average. Data were plotted as daily mean clinical score for all animals in a particular treatment group. Scores of asymptomatic mice $($ score $=0)$ were included in the calculation of the daily mean clinical score for each group.

\subsection{Histological Studies.}

CNS tissues from five representative animals from the experimental groups were dissected between 21-24 days after immunization. The brain, cerebellum and spinal cord were fixed and embedded in paraffin. Paraffin-embedded tissues were cut on a microtome (5 $\square \mathrm{m}$ thickness) and incubated sequentially with anti Mac1/CD11b (macrophages/microglia), horseradish peroxidase-conjugated anti-goat antibody, and diaminobenzidine chromogen. Histological examination was performed with a Nikon Eclipse 90i (Nikon Instruments Inc, (Amstelveen, The Netherlands) connected to a DXM1200C digital camera (Nikon Instruments Inc, Amstelveen, The Netherlands). Hematoxylin was used for background staining. Sections from 4-10 segments per mouse were examined blindly by one investigator.

\subsection{Intravital Microscopy in Mouse Brain}

Intravital microscopy of the mouse cerebromicrovasculature was performed as previously described [18]. Briefly, the mice were anesthetized by i.p. injection of a mixture of $100 \mathrm{mg} / \mathrm{kg}$ Ketamine and $10 \mathrm{mg} / \mathrm{kg}$ Xylazine and the tail vein was cannulated for administration of fluorescent dyes. A craniotomy was performed using a high-speed drill (Dremel, Madrid, Spain) and the dura matter was removed to expose the underlying pial vasculature. The mouse was maintained at $37{ }^{\circ} \mathrm{C}$ throughout the experiment and the exposed brain was continuously superfused with artificial cerebrospinal fluid buffer $(132 \mathrm{mM} \mathrm{NaCl}, 2.95 \mathrm{mM} \mathrm{KCl}, 1.71 \mathrm{mM}$ 
$\mathrm{CaCl}_{2}, 0.64 \mathrm{mM} \mathrm{MgCl}, 24.6 \mathrm{mM} \mathrm{NaHCO} 3,3.71 \mathrm{mM}$ dextrose and $6.7 \mathrm{mM}$ urea, $\mathrm{pH}$ 7.4) at $37^{\circ} \mathrm{C}$.

In order to observe leukocyte/endothelium interactions, leukocytes were labelled in vivo immediately before each recording, using rhodamine-6G (5 mg/kg body weight). Mice were injected via the tail vein with $200 \mu \mathrm{l}$ of a $0.05 \%$ rhodamine- $6 \mathrm{G}$ solution: $5 \mathrm{mg}$ of rhodamine6G were dissolved in $10 \mathrm{ml}$ of $0.9 \%$ saline solution. Rhodamine $6 \mathrm{G}$ selectively stains mitochondria and achieves $99.99 \%$ staining of leukocytes for up to 5 min after injection of the concentration used in this study [18]. Then, leukocytes were examined using a Zeiss Axioplan 2 (Thornwood, NY, USA) imaging microscope connected to an AxioCam MR digital camera using the AxioVision AC imaging software and an Acroplan 20x/0.50W Ph2 lens. Eight different postcapillary venules of diameter between 30 and $70 \mu \mathrm{m}$ were chosen for observation. All experiments were recorded for later analysis. Rolling leukocytes were defined as white cells moving at a velocity less than that of erythrocytes. Leukocytes were considered adherent to the venular endothelium if they remained stationary for $30 \mathrm{~s}$ or longer. Leukocyte adhesion was expressed as cells $/ \mathrm{mm}^{2}$ of venular surface area, as shown previously [19].

\subsection{Experimental Protocol for Intravital Microscopy}

Leukocyte rolling and adhesion was observed by intravital microscopy at day 21-24 post immunization with $\mathrm{MOG}_{35-55}$. Animals were subjected to different protocols corresponding to different treatment with $\mathrm{OA}$ as mention above: Mice were treated daily with $50 \mathrm{mg} / \mathrm{kg} / \mathrm{d}$ OA from either day 7 (OA2) or 12 (OA1) post immunization. 


\subsection{BBB Permeability Measurement.}

In order to evaluate BBB disruption induced by EAE induction, we measured the extravasation of Evans Blue dye (EB) as a marker of albumin extravasation. At 21-24 days following EAE induction, mice were injected i.p. with $1 \mathrm{ml}$ of $4 \%$ w/v Evans Blue. After $4 \mathrm{~h}$, mice were sacrificed, perfused, and brain and spinal cord were removed. Dye was extracted from the CNS tissue for 2-3 days in formamide (4 ml/g of wet tissue) at room temperature. Extracted dye concentration was determined by measuring the absorbance at $650 \mathrm{~nm}$. CNS tissue was dried $24 \mathrm{~h}$ at $60^{\circ} \mathrm{C}$ and weighed.

Calculations were based on external standard readings, and extravasated dye was expressed as $\mu \mathrm{g}$ of Evans Blue/mg dried weight of brain tissue.

\subsection{Assays for Cytokines, Chemokines and Adhesion Molecules Levels Detection}

Mice ( $\mathrm{n}=7$, per group) were treated i.p with $50 \mathrm{mg} / \mathrm{kg} / \mathrm{d}$ OA as mentioned above. Animals were sacrificed at day 20-24 post-immunization and CNS tissue samples (cerebral cortex, cerebellum and spinal cord) were prepared by homogenization in ice-cold PBS supplemented with protease inhibitor cocktail (Sigma-Aldrich, St Louis, MO, USA) using a tissue-tearor homogenizer (Cole-Parmer Instrument, IL, USA.). The samples were then centrifuged for 15 min at $4000 \mathrm{rpm}$ in order to separate extracellular supernatant from the cell pellet. Aliquots of supernatant were prepared and stored at $-80{ }^{\circ} \mathrm{C}$ until cytokine assays were performed. OPN, ICAM-1, TNF $\alpha$ and IL-10 levels were examined by commercial ELISA kits following manufacturer's instructions. The concentration of the cytokines was determined by extrapolation from the appropriate standard curve, and was expressed as $\mathrm{pg} / \mathrm{mg}$ total protein.

Th1 cytokines and chemokines (TNF $\alpha$, IFN $\gamma$, MCP-1 and MIP-1 $1 \alpha$ ) were assayed from plasma using a multiplex assay kit (Lincoplex, Linco Research, St. Charles, MO, USA) 
according to the instructions of the manufacturer. Assay standard curves were created with the stock provided by the kit, and the assay buffer served as the background ( 0 concentration). The concentrations of the cytokines were calculated by matching the optical density of the samples against a regression equation established with the standard curve. The assay was performed in duplicate for the background, standards, controls, and samples.

\subsection{Detection of Auto-antibodies}

Serum was collected from animals on day 21 after immunization. Level of antibodies directed against MOG was determined using the enzyme-linked immunoassay (ELISA) technique. 96well polystyrene microtiter plates were coated with $0.5 \mu \mathrm{g} /$ well of $\mathrm{MOG}_{35-55}$ peptide by overnight incubation in PBS at $4{ }^{\circ} \mathrm{C}$. After blocking with 5\% BSA, the wells were incubated in duplicate with the serum samples diluted 1:60 in PBS plus $10 \%$ FCS for $2 \mathrm{~h}$ at $20^{\circ} \mathrm{C}$. After washing, HRP-conjugated goat anti-mouse IgG, IgG1 or IgG2a polyclonal antibodies were subsequently added for $90 \mathrm{~min}$. After another washing, adding the substrate, and arresting the reaction with $0.1 \mathrm{~N} \mathrm{HCl}$, absorbance was read at $450 \mathrm{~nm}$. The results were expressed as mean optical density at $450 \mathrm{~nm}$.

\subsection{Statistical Analyses}

Statistical analysis was performed with the GraphPad Prism Version 4 software (San Diego, CA, U.S.A.) by analysis of variance (ANOVA). Analyses were performed using two way RM-ANOVA for comparison clinical parameters, and one-way ANOVA for comparison of parameters (cytokines, extravasation, leukocytes and MOG antibodies) at day 21 postinfection. A post hoc analysis was made by the Bonferroni's multiple comparison test. Results are expressed as mean $\pm \mathrm{SD} ; P$ values $<0,05$ were considered statistically significant. 


\section{Results}

\subsection{Oleanolic acid reduces clinical signs}

Oleanolic acid belongs to the oleanane-type triterpenoids, and although it has been shown to inhibit immuno-inflammatory responses, no effects of OA on MS have been reported. Therefore, we decided to evaluate the effect of $\mathrm{OA}$ on a murine experimental model of multiple sclerosis, EAE, at a dose previously proved to be both safe and therapeutically relevant in rodents $[20,21]$.

To this end, we induced EAE in C57BL/6J mice as described previously by immunization with $\mathrm{MOG}_{35-55}$ on day 0, and daily injected i.p. either vehicle or $50 \mathrm{mg} / \mathrm{kg} \mathrm{b.w.} \mathrm{OA,} \mathrm{when}$ clinical symptoms were detected (OA1) or before the onset of the disease (OA2) until the end of the experiment. As seen in Fig 2A,B, signs of paralysis started to develop around days 1114 (tail atony and clumsy gait) following immunization, pointing to EAE induction; such signs quickly became more apparent over the next 6-7 days and then stabilized temporarily (Fig. 2A,B). In addition, a progressive loss of body weight paralleled with a higher severity of the disease, in fact, on day 20 weight loss reached approximately $3 \mathrm{~g}$ for mice weighing $19 \mathrm{~g}$ on day 0 (Fig. 2C,D). By contrast, these two critical parameters were significantly less severe in both OA1 and OA2 groups: the treatment inhibited or delayed clinical manifestations $(p<$ 0.001 versus control on day 20) and body weight loss ( $p<0.001$ versus control on day 20) associated with EAE. In these experiments, we demonstrated that a daily dose of OA initiated 7 days post-immunization delays the onset of EAE (Fig 2B) and body weight loss (Fig 2D). In addition, the clinical status of the mice whose treatment started at day 12 after immunization (OA1) (once symptoms arose) remained stable (middle score) during the following 12 days 
(Fig. 2A), while untreated animals progressively deteriorated. This OA1 group also showed a remarkable improvement in body weight (Fig. 2C). The effect observed on the weight parameter is not the result of a direct effect of the compound on weight gain, because the molecule itself does not affect the weight of healthy animals (data not shown).

We next performed experiments to assess the impact of oleanolic acid treatment on the long term evolution of clinical symptoms (endpoint: tetrapegic stage). In figure 3 we show both evolution of clinical symptoms (Fig. 3A), and time to maximum score using Kaplan-Meier survival analysis (Fig 3B). Although in all groups, mice continued to deteriorate over the time, OA1- and OA2-treatments delayed the clinical disease. The average clinical score on both OA-EAE groups was 2.5 (partial hind limb paralysis) at the time of maximum score of untreated EAE-mice (score of 4) was achieved, and body weight loss by day 40 was approximately $20 \%$ for OA1 and $16 \%$ for OA2, opposed to $50 \%$ for untreated EAE-animals (data not shown), indicating a marked amelioration of symptoms by OA. Mice that developed severe EAE (score of 4) were euthanized at this time. Differences in clinical evolution for the treated EAE mice were not found significant between OA1 and OA2 groups.

\subsection{Expression of cytokines and chemokines in the CNS and serum of OA-treated EAE mice}

To investigate whether the diminished EAE severity resulting from OA treatment could be associated with a reduced immune-inflammatory reaction, we studied both cellular and humoral responses. Thus, the modulation of some inflammatory events, such as accumulation of cytokines or adhesion molecules, in the sera or CNS tissue of OA treated EAE mice was first examined. 
We studied the levels of osteopontin (OPN), a proinflammatory cytokine, and ICAM-1, an adhesion molecule, in CNS tissue extracts at day 21-24 after disease induction. In agreement with clinical signs, the concentration of OPN and ICAM-1 (Fig.4A,B) in cerebral cortex, cerebellum and spinal cord of EAE mice was significantly increased compared with control animals. In contrast, both OA1 and OA2 treatment notably diminished the expression of both proteins. As shown in Fig. 4A, OPN decreased up to $60 \%$ in the spinal cords of OA1-treated EAE mice with a mean of $(377 \pm 48) \mathrm{pg} / 100 \mathrm{mg}$ tissue, and $63 \%$ in the spinal cords of OA2treated EAE-mice with a mean of $(347 \pm 65) \mathrm{pg} / 100 \mathrm{mg}$ tissue compared with $(949 \pm 68)$ $\mathrm{pg} / 100 \mathrm{mg}$ tissue in untreated EAE mice $(\mathrm{p}<0.001)$. In cerebellum the levels of OPN in EAE mice and controls were $(507 \pm 45) \mathrm{pg} / 100 \mathrm{mg}$ tissue and $(165 \pm 17) \mathrm{pg} / 100 \mathrm{mg}$ tissue, respectively, and a decrease of $53.2 \%$ in OA1-treated EAE mice with a mean of $(237 \pm 36)$ $\mathrm{pg} / 100 \mathrm{mg}$ tissue, and $51,8 \%$ in OA2-treated EAE-mice with a mean of $(244 \pm 18) \mathrm{pg} / 100 \mathrm{mg}$ tissue was observed, compared with untreated EAE mice $(\mathrm{p}<0.001)$. In cerebral cortex the levels of OPN in EAE mice and healthy controls were of $(101.6 \pm 6.2) \mathrm{pg} / 100 \mathrm{mg}$ tissue and $(33.9 \pm 2.6) \mathrm{pg} / 100 \mathrm{mg}$ tissue, respectively, and a decrease of $49.3 \%$ in OA1-treated EAE mice with a mean of $(51.2 \pm 10) \mathrm{pg} / \mathrm{mg}$ tissue and $51 \%$ in OA2-treated EAE-mice with a mean of $(49.4 \pm 11) \mathrm{pg} / \mathrm{mg}$ tissue was observed as compared with untreated EAE mice $(\mathrm{p}<0.001)$.

In addition, as shown in Fig. 4B, ICAM-1, an important endothelial adhesion molecule involved in recruiting cells into the brain, was highly expressed on the CNS tissues obtained from EAE-mice: $(117 \pm 9.8) \mathrm{pg} / 100 \mathrm{mg}$ spinal cord, $(59.9 \pm 9.1) \mathrm{pg} / 100 \mathrm{mg}$ cerebellum and $(11.6 \pm 1.2) \mathrm{pg} / 100 \mathrm{mg}$ cerebral cortex. In contrast, detected levels of ICAM-1 significantly decreased in tissues obtained from OA-treated EAE-mice, as expected. In OA1- or OA2treated EAE-mice, ICAM-1 expression diminished in spinal cord by $80.2 \%$ and $79.7 \%$ 
respectively, in cerebellum by $81 \%$ and $82 \%$ respectively, and in cerebral cortex by $81 \%$ and $84.5 \%$, respectively.

In order to determine the effect of OA treatment in the production of inflammatory mediators, we next examined in sera the levels of Th1 cytokines, $\mathrm{TNF} \alpha$ and IFN $\gamma$, as well as the chemokines MCP-1 and MIP-1 $\alpha$ at day 21-24 after disease induction. As shown in Fig. 5A, any OA treatment (before or after the clinical onset) diminished the presence of the screened cytokines and chemokines compared with untreated mice. Accordingly, the high levels of TNF $\alpha$ detected in spinal cord tissue of EAE-mice decreased by $56 \%$ in both OA1- or OA2treated EAE-animals as compared to untreated ones, whereas Th2 cytokine IL-10 expression increased significantly (Fig. 5B).

\subsection{Effect of OA treatment on the humoral immune phase on EAE mice.}

We next evaluated whether OA treatment also targeted the antigen-specific immune response in EAE animals. We determined the anti-MOG total $\mathrm{IgG}, \mathrm{IgG} 1$, and $\operatorname{IgG} 2 \mathrm{a}$ titers by ELISA in serum samples obtained on day 21 after immunization. As shown in Fig. 5C anti-MOG total IgG could only be measured in sera from EAE mice, whereas healthy animals showed an almost complete absence of anti-MOG antibody titers. In addition, EAE mice treated with OA, either OA1 or OA2 protocol, showed a significant reduction in this marker of humoral immune reaction. At a serum dilution of 1:60, the mean optical density (OD) measured at $450 \mathrm{~nm}$ was $0.709 \pm 0.100$ and $0.703 \pm 0.095$ in OA1- and OA2-treated EAE mice, respectively. In vehicle-treated EAE mice the mean OD values observed were $1.744 \pm 0.116$ ( $n=7$ for each group), and in control animals OD values were $0.064 \pm 0.004(n=7)$. Curiously, in untreated EAE mice the expression levels of the IgG1 isotype were higher than those of IgG2a, but while anti-MOG IgG1 titers diminished after OA treatments, anti-MOG IgG2a titers remained unchanged. 


\subsection{Oleanolic Acid reduces infiltration in EAE mice.}

Paralleling the immune-inflammatory parameters studied above, CNS tissue sections were also incubated with anti-Mac-1/CD11b, a marker for macrophages/microglia, in order to detect the effect of OA on infiltrating/intrinsic inflammatory cells.

Inflammatory cells are found within the CNS in acute EAE and are associated with clinical signs. As shown in Figure 6, an abundance of inflammatory cells was present either in spinal cord or in the granular layer of cerebellum of EAE mice, as expected (qualitative evaluation), while positive staining was not observed in CNS tissue sections of control mice. These cells showed morphology of macrophage-like or/and of ramified microglia (microglial-like cells). However, in OA treated EAE mice a substantially reduced infiltration was observed, as judged by a minimal CD11b/Mac-1 immunoreactivity on the different tissue sections, these results being linked to an improvement of the clinical symptoms of EAE.

\subsection{Effect of OA treatment on leukocyte recruitment in the CNS microvasculature of EAE mice.}

Previous studies have shown that cellular recruitment from the circulation to the CNS can be visualized by intravital microscopy techniques. These experiments have demonstrated that the mononuclear cells infiltrate around and within the pial venules of EAE mice [19]. Therefore, in this study we used intravital microscopy to directly observe leukocyte-endothelial interactions in the cerebral-microvasculature of EAE mice and investigate whether OA treatment, after or before the onset of the disease, modulate this recruitment. Leukocyteendothelial cell interactions were evaluated at day 21-24 post-immunization, when the group of untreated mice showed hind limb paralysis. 
Very little adhesion (Fig. 7A) and no leukocyte rolling (Fig. 7B) were observed in the brain microcirculation of healthy control mice. In contrast, an increase for both rolling and adhesion was observed in brain of EAE mice. Around 38 rolling cells/min and 15 adherent cells/area/min were observed in postcapillary venules of symptomatic mice. However, in EAE animals that were treated with OA after or before the onset of physical symptoms (both OA1 and OA2), the adhesive events diminished significantly when compared to untreated animal, and a similar reduction was noted in the rolling events. Interestingly, OA treatment in presymptomatic mice (OA2) led to a remarkably more effective leukocyte recruitment reduction than $\mathrm{OA}$ treatment in symptomatic mice (OA1), 55\% vs 35\% respectively. Representative photos of the different treatments (Fig. 7C) illustrate the reduction in adhesion capability in the presence of OA.

\subsection{Effect of OA treatment on blood-brain barrier disruption of EAE mice.}

Blood-brain barrier (BBB) breakdown is another underlying event in the pathogenesis of EAE, and because of the diminished cellular infiltration of the CNS in OA-treated EAE mice, we examined finally the BBB integrity.

Since Evans Blue dye binds to albumin in the blood, extravasation of the dye serves as a marker for BBB permeability and neurovascular damage. Therefore, CNS tissues were processed and analysed to detect Evans Blue dye extravasation in treated or untreated OA mice (both EAE and healthy) at day 21-24 postimmunization, when untreated EAE mice exhibited hind limb paralysis. As shown in Fig. 8, all three CNS tissues of EAE mice revealed a marked increase in the permeability of the BBB compared to healthy animals, especially in cerebellum and spinal cord. However, this enhanced permeability was significantly reduced in both OA1- and OA2- treated mice. The measurements of Evans Blue extravasation did not 
1

significantly differ between both groups of OA-treated mice, EAE+OA1 or EAE+OA2. Neither was any variance found between treated and untreated healthy mice.

Thus, the changes in BBB function during EAE may also be modulated by OA treatment. 


\section{Discussion}

Multiple sclerosois (MS) is a multiphasic autoimmune CNS disease for which no cure is presently known. The adverse events associated with the widely used interferon- $\beta$, glatiramer acetate and mitoxantrone fully justify the search for alternative and less detrimental drugs. Much research has focused on new therapeutic approaches to inhibiting the immuneinflammatory processes that are believed to initiate CNS damage in MS. Oleanolic acid is an excellent candidate to be considered as an immunomodulatory agent for the treatment of MS patients, since oleanane triterpenoids are multifunctional drugs that exhibit both antiinflammatory and neuroprotective activities, targeting multiple cytokines and key signaling molecules important in neurodegenerative disorders $[13,16,22]$.

We used a model of nonrelapsing, chronic sustained form of disease and demonstrated for the first time that $\mathrm{OA}$, at a dose previously proved safe and therapeutically active on rodents $[20,21]$, undoubtly inhibited the development of EAE in treated mice using two different trial protocols: after (OA1, therapeutic) or before (OA2, semiprophylactic) the appearance of early clinical signs. In both, OA1- and OA2-treated mice, the pathological hallmarks of MS - Th1 response, blood brain barrier disruption, infiltration of immune cells through the endothelium of the $\mathrm{BBB}$, and their subsequent entry into the CNS, as well as microglial activation - were significantly diminished and accompanied by a remarkable attenuation of the severity of clinical symptoms and a delay in their onset as compared with vehicle-treated animals.

At first sight, the broad effectiveness of OA on multiple signs of EAE indicates that it may affect an early phase in the immuno-inflammatory response leading to EAE, which was confirmed by the finding that triterpene attenuated the generation of certain Th1 cytokines and chemokines which are critical for the progression of the disease. We observed that OA promoted a dramatic decrease in OPN and TNFo levels expressed in CNS tissues of EAE mice, and diminished the presence in sera of soluble TNF $\alpha$, IFN- $\gamma$, MIP- $1 \alpha$ or MCP-1. 
Conversely, secretion of Th2 cytokines such as IL-10 was induced, as increased levels of these were found in the spinal cord of EAE-treated mice. This increase in IL-10 concurrent with decreases in TNF $\alpha$ and IFN- $\gamma$ could potentially be considered as a favorable shift in Th1/Th2 bias, since EAE induction is associated with Th1 cytokines but Th2 cytokines cause recovery from the disease [23]. In addition, because of the potential therapeutic effect of IL10 on autoimmune diseases, it is worth noting the significant $(P<0.001)$ increase in IL-10 in healthy OA-treated mice compared with vehicle-treated animals, which opens a new consideration for the profilactic administration of OA (under evaluation).

However, not only Th2 cells can secrete IL-10, but it can also be produced by other cell types, such as macrophages, dendritic cells or B cells, being therefore considered by some investigators, as an immunoregulatory cytokine [24]. In fact, the protective changes in TNF- $\alpha$ and IL-10 frequently observed in MS and EAE during pregnancy or with estriol treatment represents an immunoregulatory, rather than a Th2, environment [25].

There is then a clear concordance between the mildness of clinical symptoms in OA-treated animals and the cytokine profile found, although we will explore in further studies whether these changes represent an immunoregulatory or a Th2 phenotype.

OPN, in particular, is considered a potent modulator of autoimmune demyelinating diseases, and studies on $\mathrm{OPN}^{-/-}$knockout mice have confirmed its pivotal role in controlling Th1/Th2 polarization. Although $\mathrm{OPN}^{-1-}$ knockout mice develop EAE, these mice display an evolution and severity of the disease distinct from their wild-type littermates. Such mice exhibit decreased inflammatory infiltrates and diminished production of IFN- $\gamma$, TNF $\alpha$ and IL-12, but increased IL-10 levels [26]; this evidence is consistent with the general cytokine-profile found here. 
On the other hand, the occurrence of high levels of TNF $\alpha$ are mainly associated with changes in BBB permeability, as well as with the presence of inflammatory mediators and cells infiltrated in CNS tissues both in MS patients [27] and in EAE models [28]. As previously reported, we have found high levels of $\mathrm{TNF}_{\alpha}$ both in serum and spinal cord of EAE mice, which are associated with increased neurovascular permeability (under the assumption that its presence in spinal cord may be due to activated CNS-resident cells or to TNF $\alpha$-positive cells from the circulation).

Consistent with high TNFo levels, we also found elevated expression of the adhesion molecule ICAM-1, which has been demonstrated to be necessary for inflammatory cell trafficking through post-capillary venules into the brain parenchyma and whose upregulation is dependent upon TNF $\alpha$ production triggered by the loss of BBB integrity [29]. Interestingly, we found that OA-induced suppression of inflammatory mediators correlates with the profile of its actions on BBB permeability and on cell infiltration into the CNS.

In addition, CNS tissues of EAE mice treated with OA, both therapeutically or semiprophylactically, exhibited diminished levels of ICAM-1 compared with untreated EAE mice. In this study, intravital fluorescence microscopy of cerebral microvasculature revealed that OA-treated EAE mice present a diminished leukocyte rolling and adhesion when compared with that observed in untreated EAE mice. Therefore, it is possible that OA blocks leukocyte recruitment to brain by reducing ICAM-1 expression.

The inflammatory response found in EAE mice is closely related to BBB damage [5]. Irrespective of the clinical forms of EAE, BBB breakdown is a hallmark in the development of EAE, as well as in human MS which exacerbates the inflammatory response by providing circulating cells and factors the access to privileged CNS tissues, and soluble CNS products access to the circulation. The precise mechanisms mediating the onset of BBB dysfunction are still controversial. Besides inflammatory cytokines including TNF $\alpha$ and IL-1 [30], or enzymes 
such as metalloproteinases [31], disruption of CNS homeostasis can occur in the absence of important inflammatory mediators through the action of factors such as arachidonic acid metabolites [32] and free radicals such as peroxynitrite [33] or NMDA receptor agonists [34]. In the present study, we observed that the loss of BBB integrity in C57BL/6J EAE-mice presents tissue differences, and similar to what has been previously found in other EAE-mice models, BBB permeability was predominantly disrupted in the cerebellum and spinal cord [35]. In addition, these regional differences in BBB permeability closely correlated with the expression pattern of parameters that contributes to inflammation and cell accumulation: OPN and ICAM-1 upregulation was also prominent in cerebellum and spinal cord. Therefore, it can be hypothesized that the expression of these molecules may either contribute to, or be induced in conjunction with BBB permeability changes, although such is not the goal of this study. Daily OA treatment, starting before or after the onset of the disease, significantly inhibited $\mathrm{BBB}$ disruption in all CNS tissues of EAE mice. It remains to be further investigated whether OA actions in neurovascular functions during EAE are exclusively related to its antiimmune/inflammatory properties or represent pleiotropic effects. Although some natural triterpenes have shown neuroprotective effects [36], inhibitory properties in arachidonic-acidmetabolizing enzymes [37], anti-oxidative properties and membrane-stabilizing actions [20], and inhibitory activity in the induction of ICAM-1 [38], no study to our knowledge had in fact been performed linking these actions to BBB integrity.

Finally, although major attention is usually given to these Th-cell-mediated events in EAE, specific autoantibodies and B cell responses are also thought to contribute to the exacerbation of experimental and human MS [39]. Consistent with what has previously been reported, we found in this study that MOG-induced EAE showed higher concentrations of anti-MOG IgG antibodies of the IgG1 isotype than of the IgG2a isotype [40,41]. The continuous administration of OA (OA1 and OA2) significantly reduced IgG MOG antibody production, 
particularly the IgG1 isotype. Thus, inhibition of the pathogenic antibodies production against MOG may also be a contributing mechanism by which OA exerts its beneficial actions on this complex autoimmune disorder. A similar inhibition of the humoral response has been previously described for IFN- $\tau$ treatment [42]. However, while IFN- $\tau$ actions suggest inhibition of $\mathrm{B}$ cell clonal expansion by induction of terminal differentiation, it remains unclear as to how OA diminishes humoral autoimmunity.

Together these findings provide a new insight into the neuroprotective actions of this natural triterpenoid. However, the precise mechanism(s) responsible for such actions as well as the major signaling molecules involved, are currently unclear and will need to be determined. In this regard, it is interesting to note that the immunomodulatory actions found for OA, such as inhibition of production of inflammatory mediators or diminished cell infiltration of the spinal cord, correlates with those described for several cannabinoid ligands, particularly agonists for CB2 cannabinoid receptors $[43,44,45]$. CB2 are highly expressed in inflammatory cells, such as microglia, cell population also sensitive to triterpenoids [16], and which respond to both kinds of molecules by reducing microglial activation and cytokine production. Thus, an attractive hypothesis to investigate, regarding underling OA mechanism of action, is whether oleanolic acid modulates the synthesis of endogenous CB ligands or its receptors, as well as the existence of a possible common mechanism and sites of action.

In summary, our findings demonstrate for the first time that the ability of oleanolic acid to ameliorate neurological signs of EAE mice is probably due to inhibitory actions in both the inflammatory arm and humoral component of the disease. Therefore, both a semiprofilactic and therapeutic administration of OA can be considered as an effective therapeutical agent for ongoing EAE and, as such, shows a promising potential for the treatment of MS in humans, as well as other Th1 inflammatory diseases. 


\section{Acknowledgements}

This work was supported by the Ramon y Cajal Program (to M. H.), F. P. I. Program from the Autonomous Government of Castilla y Leon. (to R. M.) both co-funded by F. S. E, Grants SAF2005-01242 and SAF2008-00245 from the Spanish Ministry of Science and Technology, and Grant CSI11A08 from the Autonomous Government of Castilla y Leon.

We thank D. Sanchez and J. Acebes for technical support with histological assays, J. Bermejo for valuable advice with multiplex immunoassays, J. Garcia-Sancho and J. Fernandez for microscopy facilities, and A. DeMarco for his editorial assistance.

The authors declare no financial or commercial conflict of interest. 


\section{References}

[1] Hemmer B, Archelos JJ, Hartun H P. New concepts in the immunopathogenesis of multiple sclerosis. Nat Rev Neurosci. 2002;3:291-1.

[2] Cannella, B. and Raine, C. S., The adhesion molecule and cytokine profile of multiple sclerosis lesions. Ann Neurol. 1995;37:424-5.

[3] Muller DM, Pender MP, Greer JM. Blood-brain barrier disruption and lesion localisation in experimental autoimmune encephalomyelitis with predominant cerebellar and brainstem involvement. J Neuroimmunol. 2005;60:162-9.

[4] Benveniste EN. Role of macrophages/microglia in multiple sclerosis and experimental allergic encephalomyelitis. J Mol Med. 1997;75:165-3.

[5] Karpus WJ, Ransohoff R M. Chemokine regulation of experimental autoimmune encephalomyelitis: temporal and spatial expression patterns govern disease pathogenesis. J Immunol 1998;161:2667-71.

[6] Newman DJ, Cragg GM. Natural products as sources of new drugs over the last 25 years. J Nat Prod 2007;70:461-77.

[7] Liu J. Oleanolic and ursolic acid: research perspectives. J Ethnopharm 2005;100:92-4. 
[8] Dzubak P, Hajduch M, Vydra D, Hustova A, Kvasnica M, Biedermann D, et al. Pharmacological activities of natural triterpenoids and their therapeutic implications. Nat Prod Rep 2006;23:394-411.

[9] Perez-Jimenez F, Alvarez de Cienfuegos G, Badimon L, Barja G,. Battino M, Blanco A, et al., International conference on the healthy effect of virgin olive oil. Eur J Clin Invest. 2005;35:421-4.

[10] Liu. J. Pharmacology of oleanolic acid and ursolic acid. J Ethnopharmacol $1995 ; 49: 57-68$

[11] Yim TK, Wu WK, Pak WF, Ko KM. Hepatoprotective action of an oleanolic acidenriched extract of Ligustrum lucidum fruits is mediated through an enhancement on hepatic glutathione regeneration Capacity in mice. Phytother Res 2001;15:589-92

[12] Raphael TJ, Kuttan G. Effect of naturally occurring triterpenoids glycyrrhizic acid, ursolic acid, oleanolic acid and nomilin on the immune system. Phytomedicine $2003 ; 10: 483-9$.

[13] Liby KT, Yore MM, Sporn MB. Triterpenoids and rexinoids as multifunctional agents for the prevention and treatment of cancer. Nat. Rev. Cancer 2007;7:357-69.

[14] Liu Q, Garner P, Wang Y, Huang B, Smith H., Drugs and herbs given to prevent hepatotoxicity of tuberculosis therapy: systematic review of ingredients and evaluation studies. BMC Public Health 2008;8:365. 
[15] Choi W, Han CK, Kim TK, Im GJ, Jung CM, Yun SJ, et al. Triterpene compounds which are effective on improvement of brain function. 2005 Patent Application: WO/2005/034958.

[16] Tran TA, McCoy MK, Sporn MB, Tansey MG. The synthetic triterpenoid CDDOmethyl ester modulates microglial activities, inhibits TNF production, and provides dopaminergic neuroprotection. J Neuroinflammation 2008;5:14.

[17] Guinda A, Albi T, Perez-Camino MC, Lanzon A. Supplementation oils with oleanolic acid from the olive leaf (olea europaea). Eur J Lipid Sci Technol 2004;106:22-6.

[18] Baatz H, Steinbauer M, Harris AG, Krombach F. Kinetics of white blood cell staining by intravascular administration of rhodamine 6G. Int J Microcirc Clin Exp. $1995 ; 15: 85-91$

[19] Carvalho-Tavares J, Hickey MJ, Hutchison J, Michaud J, Sutcliffe IT, Kubes P. A role for platelets and endothelial selectins in tumor necrosis factor induced leukocyte recruitment in the brain microvasculature. Circ Res 2000;87:1141-8.

[20] Senthil S, Chandramohan G, Pugalendi KV. Isomers (oleanolic and ursolic acids) differ in their protective effect against isoproterenol-induced myocardial ischemia in rats. Int J Cardiol 2007;119:131-3. 
[21] Jeong HG. Inhibition of cytochrome P450 2E1 expression by oleanolic acid: hepatoprotective effects against carbon tetrachloride-induced hepatic injury. Toxicolg Letters 1999;105:215-22.

[22] Marquez-Martin A, De La Puerta R, Fernandez-Arche A, Ruiz-Gutierrez V, Yaqoob P. Modulation of cytokine secretion by pentacyclic triterpenes from olive pomace oil in human mononuclear cells. Cytokine 2006;36:211-7.

[23] Imitola J, Chitnis T, Khoury S. Cytokines in multiple sclerosis: from bench to bedside. Pharmacol Therap 2005;106:163-77.

[24] Mocellin S, Panelli MC, Wang E, Nagerson D, Marincola FM. The dual role of IL-10. Trends Immunol 2003;24:36-43.

[25] McClain MA, Gatson NN, Powell ND, Papenfuss TL, Gienapp IE, Song F, et al. Pregnancy suppresses experimental autoimmune encephalomyelitis through immunoregulatory cytokine production. J Immunol 2007;179:8146-52.

[26] Jansson M, Panoutsakopoulou V, Baker J, Klein L, Cantor H. Attenuated experimental autoimmune encephalomyelitis in Eta-1/Osteopontin-deficient mice. $\mathbf{J}$ Immunol 2002;168:2096-9.

[27] Sharief MK, Thompson EJ. In vivo relationship of tumor necrosis factor-a $\alpha$ to bloodbrain barrier damage in patients with active multiple sclerosis. J Neuroimmunol 1992;38:27-4. 
[28] Megyeri P, Abraham C, Temesvari P, Kovas J, Vas T, Speer C. Recombinant human tumor necrosis factor constricts pial arterioles and increases blood-brain barrier permeability in newborn piglets. Neurosci Lett 1992;148:137-40.

[29] Scott GS, Kean RB, Fabis MJ, Mikheeva T, Brimer CM, Phares TW, et al. ICAM-1 upregulation in the spinal cords of PLSJL mice with experimental allergic encephalomyelitis is dependent upon TNF-alpha production triggered by the loss of blood-brain barrier integrity. J Neuroimmunol 2004;155:32-42.

[30] Royall JA, Berkow RL, Beckman JS, Cunningham MK, Matalon S, Freeman BA. Tumor necrosis factor and interleukin 1 increase vascular endothelial permeability. Am J Physiol 1989;257:L399-10.

[31] Gijbels K, Galardy RE, Steinman L. Reversal of experimental autoimmune encephalomyelitis with a hydroxamate inhibitor of matrix metalloproteases. J Clin Invest 1994;94:2177-82.

[32] Ohnishi T, Posner JB, Shapiro WR. Vasogenic brain edema induced by arachidonic acid: role of extracellular arachidonic acid in blood-brain barrier dysfunction. Neurosurgery 1992;30:545-51.

[33] Kean RB, Spitsin SV, Mikheeva T, Scott GS, Hooper DC. The peroxynitrite scavenger uric acid prevents inflammatory cell invasion into the central nervous system in 
experimental allergic encephalomyelitis through maintenance of blood-central nervous system barrier integrity. J Immunol 2000;165:6511-8.

[34] Paul C, Bolton C. Modulation of blood-brain barrier dysfunction and neurological deficits during acute experimental allergic encephalomyelitis by the N-Methyl-Daspartate receptor antagonist memantine. J Pharmacol Exp Ther 2002;302:50-7.

[35] Fabis MJ, Phares TW, Kean RB, Koprowski H, Hooper DC. Blood-brain barrier changes and cell invasion differ between therapeutic immuneclearance of neurotrophic virus and CNS autoimmunity. Proc Natl Acad Sci USA 2008;105:15511-6.

[36] Son IH, Park YH, Lee SI, Yang HD, Moon H. Neuroprotective Activity of Triterpenoid Saponins from Platycodi radix Against Glutamate-induced Toxicity in Primary Cultured Rat Cortical Cells. Molecules 2007;12:1147-52.

[37] Shen YH, Weng ZY, Zhao QS, Zeng TQ, Rios JL, Xiao WL, et al. Five new triterpene glycosides from Lysimachia foenum-graecuma and evaluation of their effect on the arachidonic acid metabolizing enzyme. Planta-Med 2005;71:770-5.

[38] Fu L, Zhang S, Li N, Wang J, Zhao M, Sakai J, et al. Three new triterpenes from Nerium oleander and biological activity of the isolated compounds. J Nat Prod 2005;68:198-206.

[39] Linington C, Bradl M, Lassmann H, Brunner C, Vass K. Augmentation of demyelination in rat acute allergic encephalomyelitis by circulating mouse 
monoclonal antibodies directed against a myelin/oligodendrocyte glycoprotein. Am J Pathol 1988;130:443-54.

[40] McQualtera JL, Darwicheb R, Ewinga C, Onukia M, Kayb TW, Hamiltonc JA, Reida HH, and Bernarda CLCA. Granulocyte macrophage colony-stimulating factor: A new putative therapeutic target in multiple sclerosis. J Exp Med 2001;194:873-82.

[41] Bischof F, Bins A, Dürr M, Zevering Y, Melms A, Kruisbeek AM. A structurally available encephalitogenic epitope of myelin oligodendrocyte glycoprotein specifically induces a diversified pathogenic autoimmune response. J Immunol 2004;173:600-6.

[42] Mujtaba MG, Streit WJ, Johnson HM. IFN-tau suppresses both the autoreactive humoral and cellular immune responses and induces stable remission in mice with chronic experimental allergic encephalomyelitis. Cell Immunol 1998;186: 94-102.

[43] Palazuelos J, Davoust N, Julien B, Hatterer E, Aguado T, Mechoulam R, Benito C, Romero J, Silva A, Guzmán M, Nataf S, Galve-Roperh I. The CB(2) cannabinoid receptor controls myeloid progenitor trafficking: involvement in the pathogenesis of an animal model of multiple sclerosis.. J Biol Chem. 2008;283: 13320-9.

[44] Arévalo-Martín A, García-Ovejero D, Gómez O, Rubio-Araiz A, Navarro-Galve B, Guaza C, Molina-Holgado E, Molina-Holgado F. CB2 cannabinoid receptors as an emerging target for demyelinating diseases: from neuroimmune interactions to cell replacement strategies. Br J Pharmacol. 2008 January; 153(2): 216-25. 
[45] Sánchez AJ, González-Pérez P, Galve-Roperh I, García-Merino A. R-(+)-[2,3Dihydro-5-methyl-3-(4-morpholinylmethyl)-pyrrolo-[1,2,3-de]-1,4-benzoxazin-6-yl]-1 naphtalenylmethanone (WIN-2) ameliorates experimental autoimmune encephalomyelitis and induces encephalitogenic $\mathrm{T}$ cell apoptosis: partial involvement of the $\mathrm{CB}(2)$ receptor. Biochem Pharmacol. 2006;72: 1697-706. 


\section{Figures}

Figure 1.- Molecular structure of Oleanolic Acid.

Figure 2.- Oleanolic acid influence on EAE disease progression. (A,B) Effect on clinical signs, and (C,D) on body weight. C57BL/J6 mice were immunized with $\mathrm{MOG}_{35-55}$ and given oleanolic acid daily i.p. from day 12 (OA1) or 7 (OA2) post-immunization until the end of the experiment (21-24 post-immunization). Arrows indicate when treatment was initiated. Values are means \pm SD. $\square$, EAE + vehicle $(\mathrm{n}=18) ; \square$, EAE + OA $50 \mathrm{mg} / \mathrm{kg}(\mathrm{n}=10) ; \square$, control + vehicle $(n=10)$. For some points, error bars are not visible because the deviations are smaller than the symbol sizes. Statistically significant differences were indicated for clinical symptoms by $* P<0.01$ and $* P<0.001$ versus untreated EAE-mice; and for body weight by $* P<0.001$ versus control and $* * P<0.001$ versus untreated EAE-mice..

Figure 3.- Effect of Oleanolic acid treatments on maximum clinical scores. (A) Effect on clinical sign evolution, and (B) on disease severity. C57BL/6 mice were immunized with $\mathrm{MOG}_{35-55}$ and given oleanolic acid daily i.p. from day 12 (OA1) or 7 (OA2) postimmunization until severe clinical sings were reached (score of 4), at this time mice were euthanized. Values are means $\pm \mathrm{SD}, \mathrm{n}=7$ in all groups. $\mathbf{\square}, \mathrm{EAE}+$ vehicle; $\square, \mathrm{EAE}+\mathrm{OA} 150$ $\mathrm{mg} / \mathrm{kg} ; \square, \mathrm{EAE}+\mathrm{OA}$. The difference between EAE-untreated and EAE-OA groups was highly significant $(P<0.001)$.

Figure 4.- OPN and ICAM-1 protein expression in CNS tissues of untreated and treated EAE mice. On day 21 after immunization with $\mathrm{MOG}_{35-55}$, protein concentrations of OPN and ICAM-1 were measured by commercial ELISA in spinal cord, cerebral cortex and cerebellum 
extracts of control, control OA, EAE, EAE+OA1, and EAE+OA2 mice. Results were expressed as the mean \pm SD from seven animals per group. Statistically significant differences were indicated by $* P<0.001$ versus control and $* * P<0.001$ versus untreated EAE-mice.

Figure 5.- Effect of OA treatments on cytokine, chemokine and anti-MOG35-55 antibody levels in EAE mice. On day 21 after immunization with $\mathrm{MOG}_{35-55}$, TNF $\alpha$, IFN $\gamma, \mathrm{MCP}-1$, MIP-1 $\alpha$ and IL-10 protein concentrations were measured, as explained in Materials and Methods, in serum samples (A) or in spinal cord extracts (B) of control, control+OA, EAE, EAE+OA1, and EAE+OA2 mice. (C) Sera were also evaluated by ELISA for titers of $\mathrm{pMOG}_{35-55}$-specific immunoglobulins at $1 / 60$ dilution. Results were expressed as the mean \pm SD from seven animals per group. Statistically significant differences were indicated by $* P<0.001$ versus control, $* * P<0.01$ versus untreated EAE-mice and $* * * P<0.001$ versus untreated EAE-mice.

Figure 6.- OA treatment improves immunohistological outcomes in spinal cords and cerebellum of EAE mice. Typical sections of cellular infiltration on spinal cord and cerebellum, at day 21 post-immunization, in control, EAE, EAE+OA1 and EAE+OA2 mice, monitored by anti-Mac-1/CD11b, a marker for macrophages/microglia, are shown. Spinal cord panels show three different histological sections visulized with a 20X lens. Cerebellum left and right panels represent a same section visulized with a $10 \mathrm{X}$ and a $20 \mathrm{X}$ lens, respectively.

Figure 7. Leukocyte recruitment to the brain over the course of EAE. Intravital microscopy was used to assess the firm arrest (A) and rolling flux (B) of leukocytes on brain 
microvasculature, at day 21 post-immunization. The protocol included control, EAE, EAE+OA1 and EAE+OA2 groups visualized on day 21 post-immunization. Results are shown as mean \pm SD of cells per minute. ${ }^{*}$ Significant $(P<0.001)$ difference compared to control, **significant $(P<0.001)$ difference compared to untreated EAE. C, Representative images of the pial microvasculature in healthy, untreated-EAE mice and OA1- or OA2-treated EAE-mice are shown. Note that the marked increase in the number of fluorescently labelled leukocytes interacting with the cerebral endothelium in EAE mice declined in EAE+OA1 and EAE+OA2 mice. In all groups, $\mathrm{n}=10$.

Figure 8.- Changes in blood-brain barrier permeability of OA treated or untreated EAE-mice. Evans blue dye was used as a measurement of plasma protein extravasation in (A) spinal cord, (B) cerebral cortex and (C) cerebellum 21-24 days post-immunization. Bars represent means $\pm \mathrm{SD}$, for $n=6$ mice. $*$ Significant $(P<0.001)$ difference compared to control, $* *$ significant $(P<0.001)$ difference compared to untreated EAE. 
Oleanolic Acid
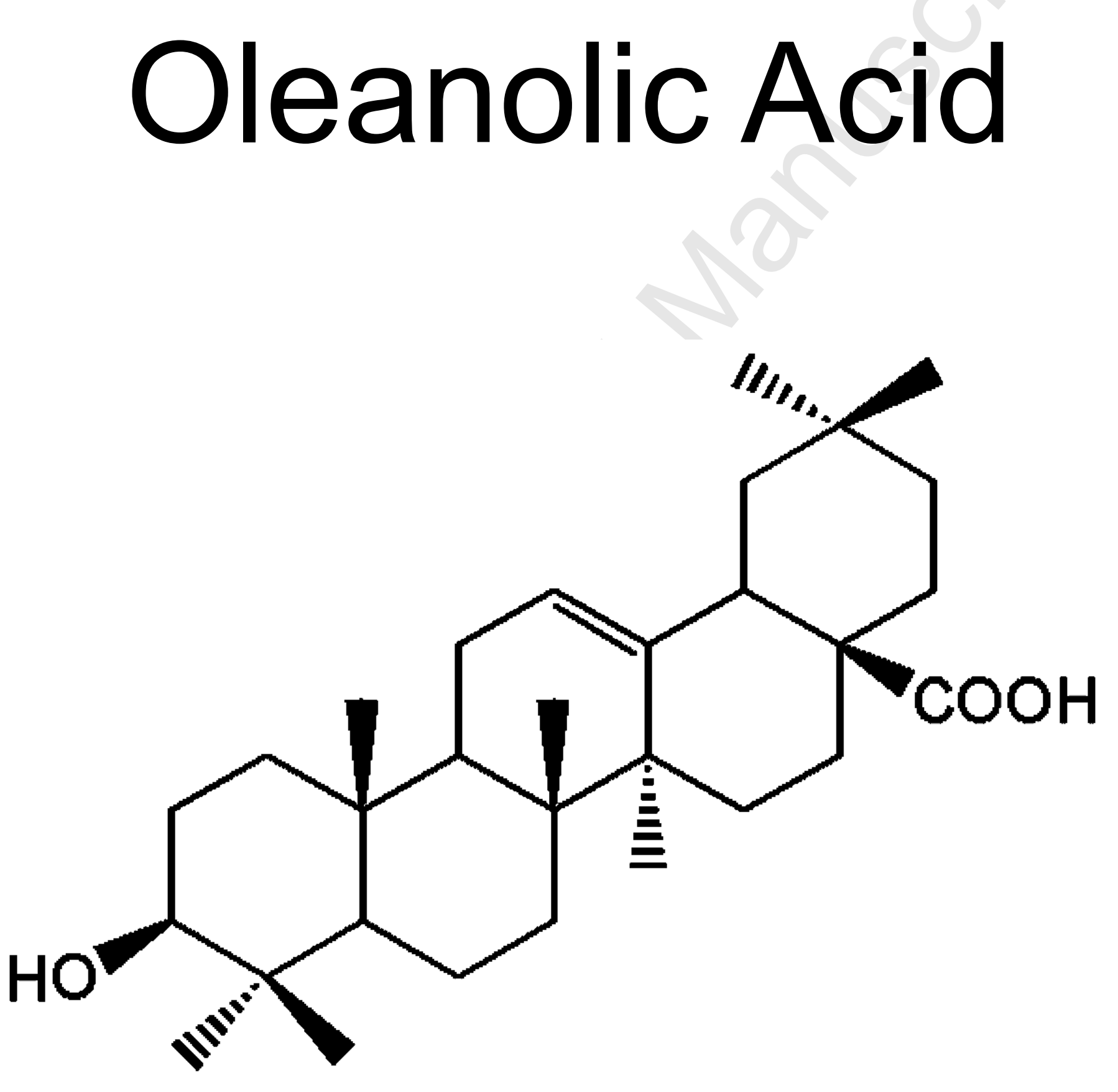

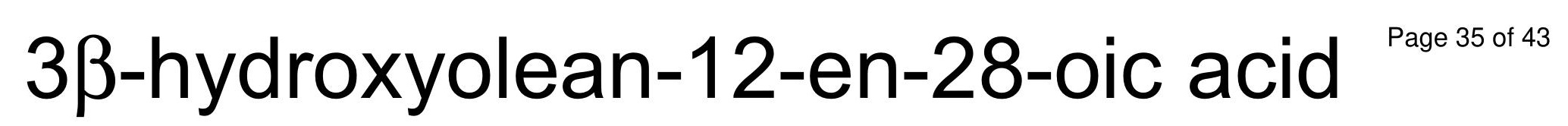

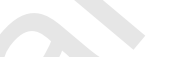


B

OA1
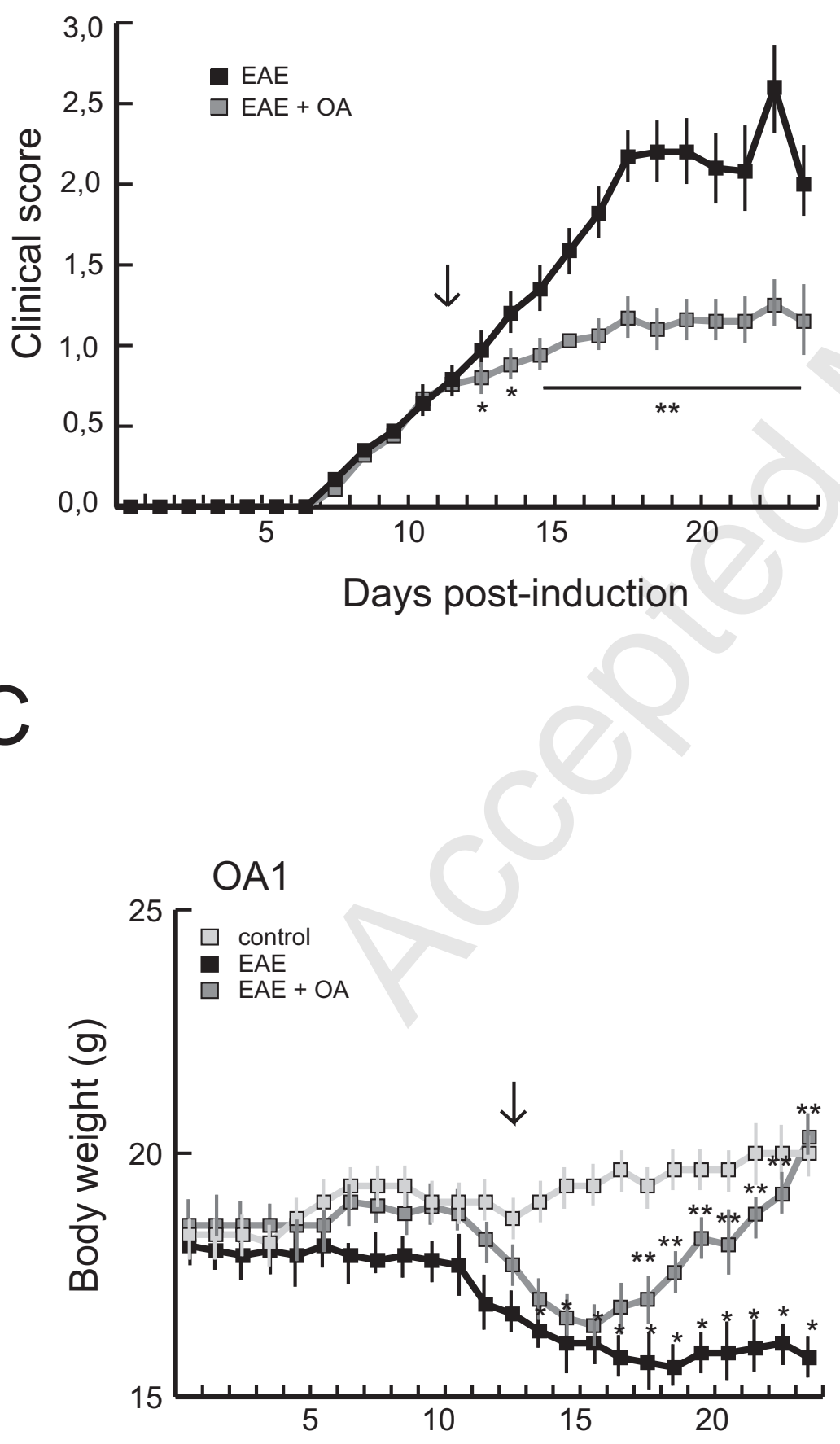

Days post-induction
OA2

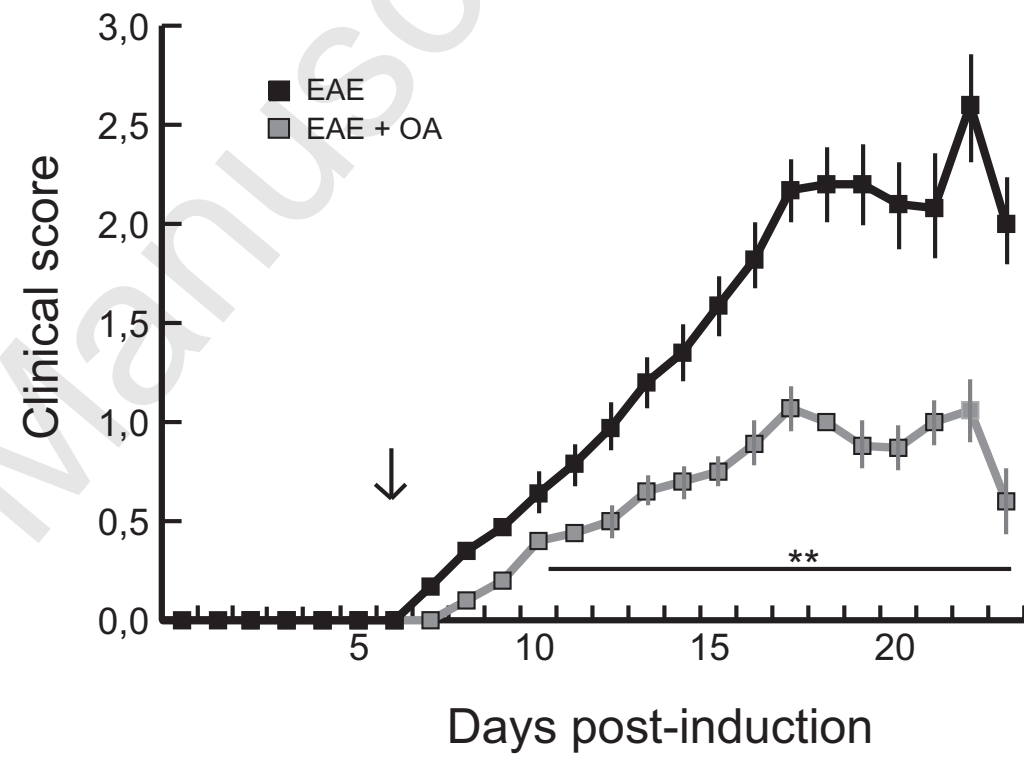

D

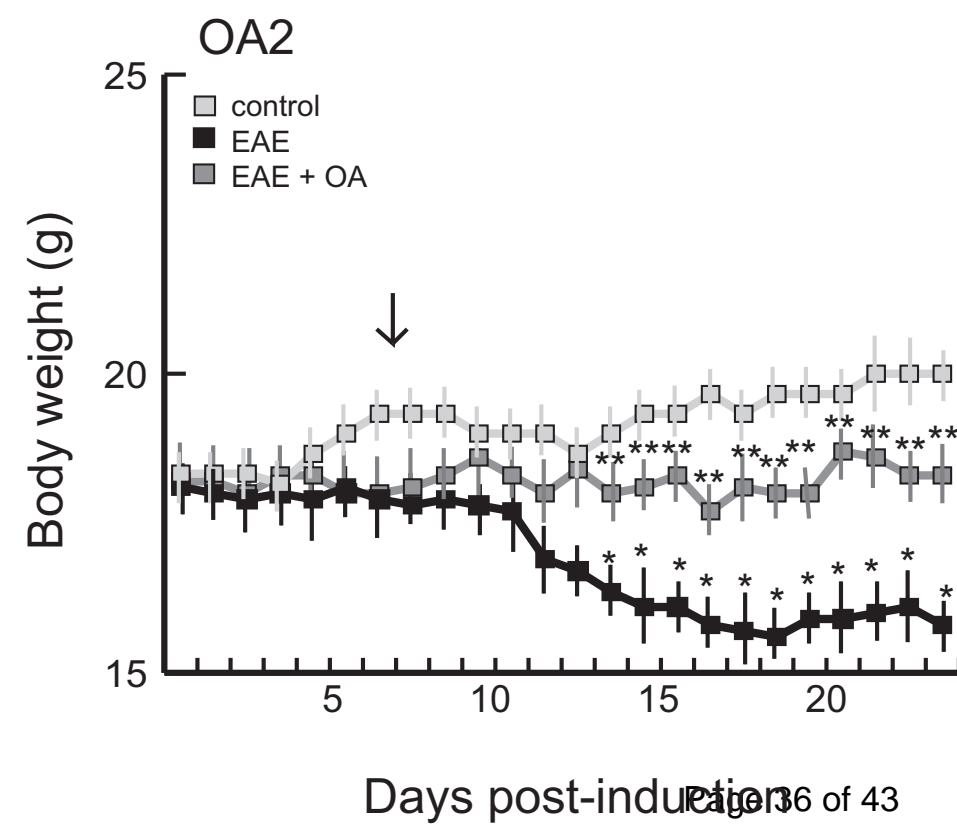


A

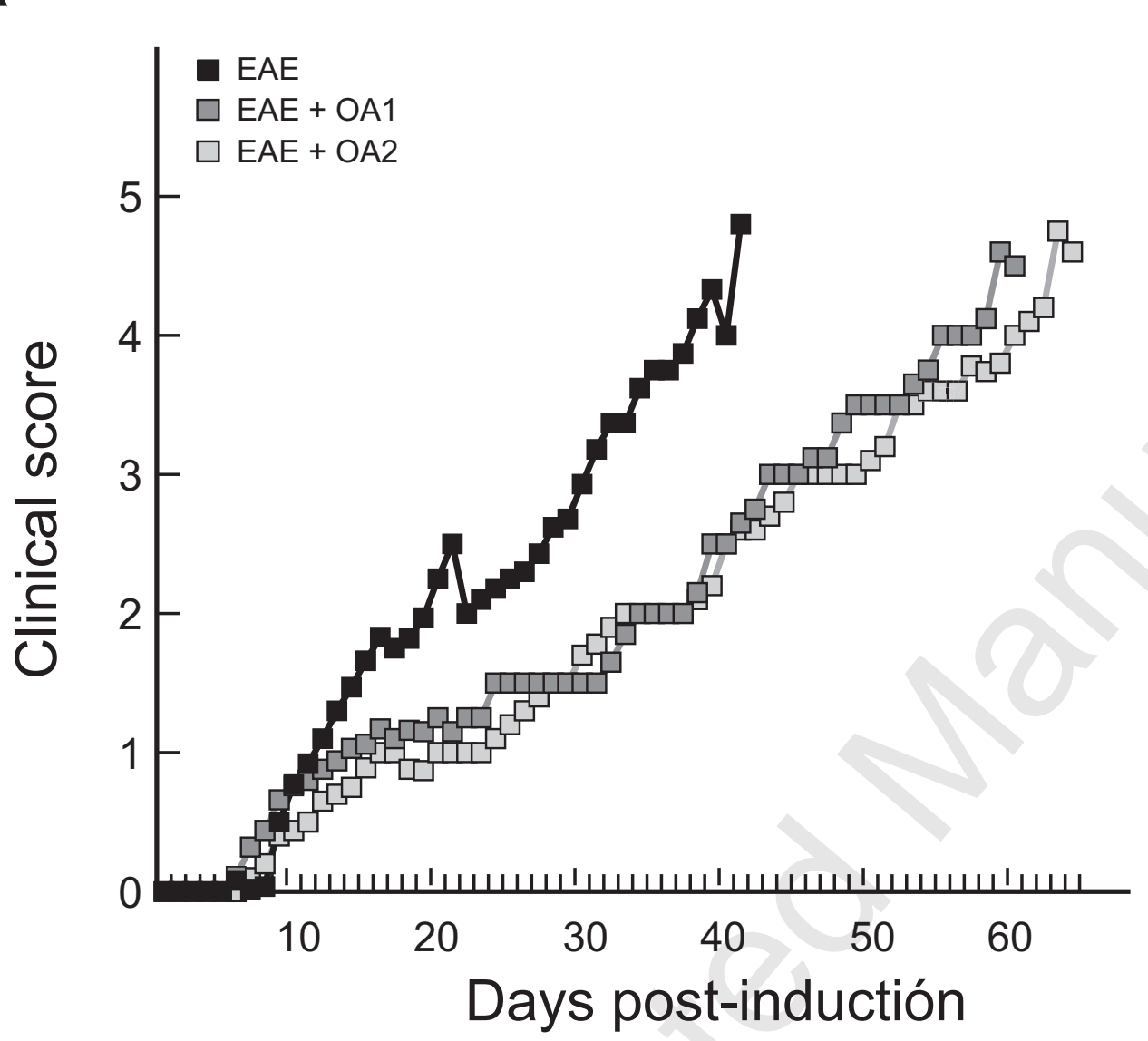

$B$

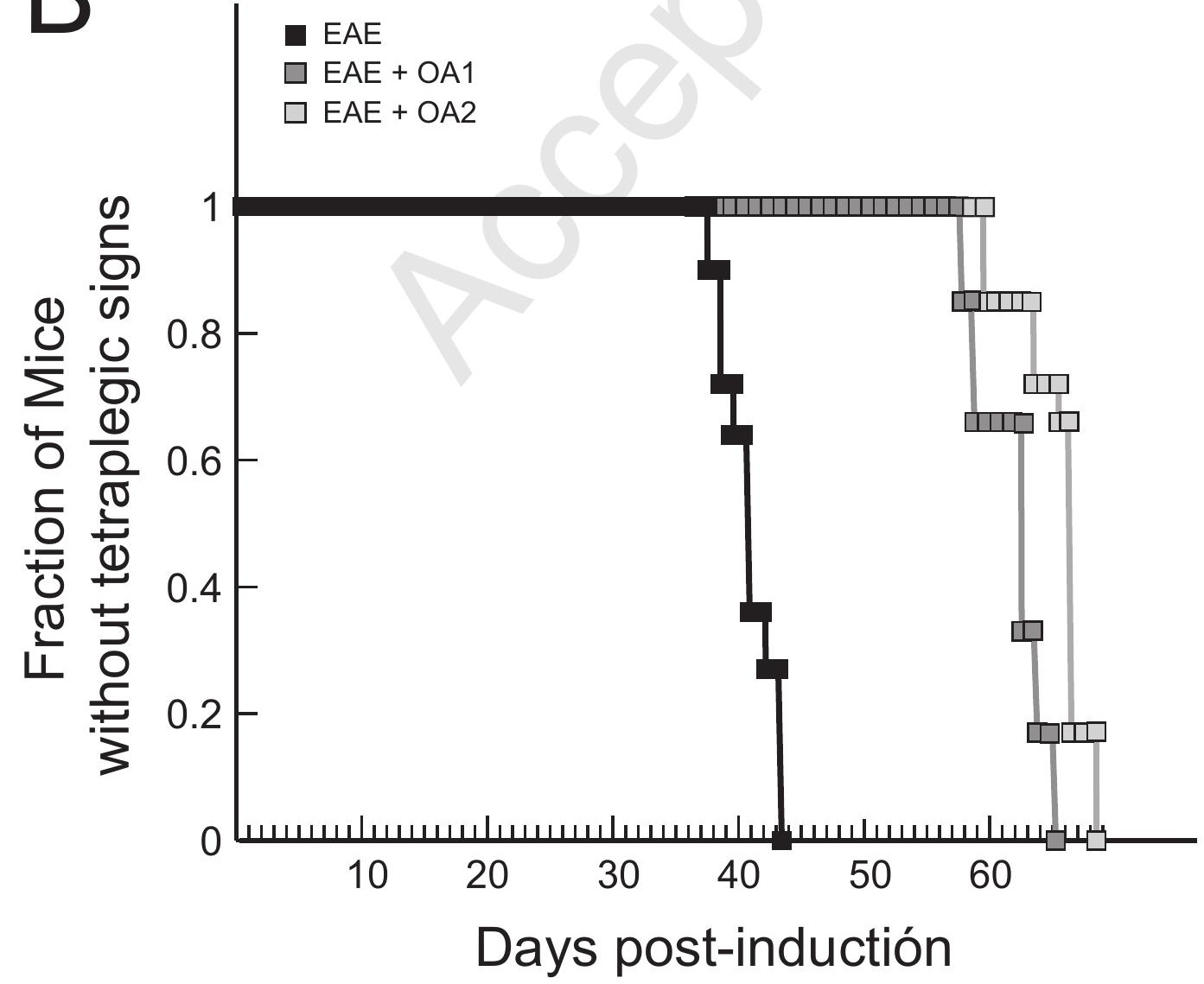

Eayspos-mincertion 


\section{Figure 4}
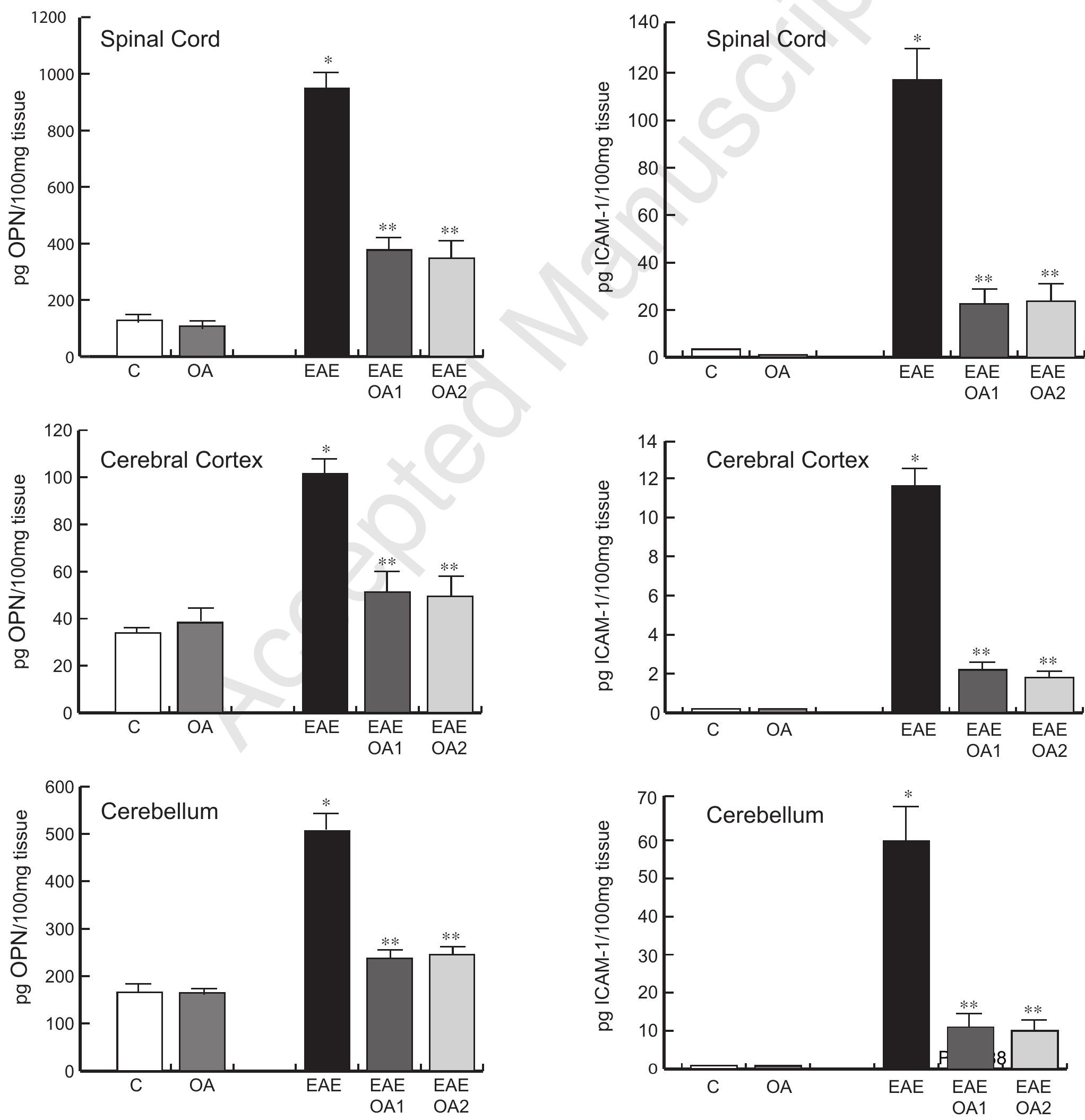
$A$
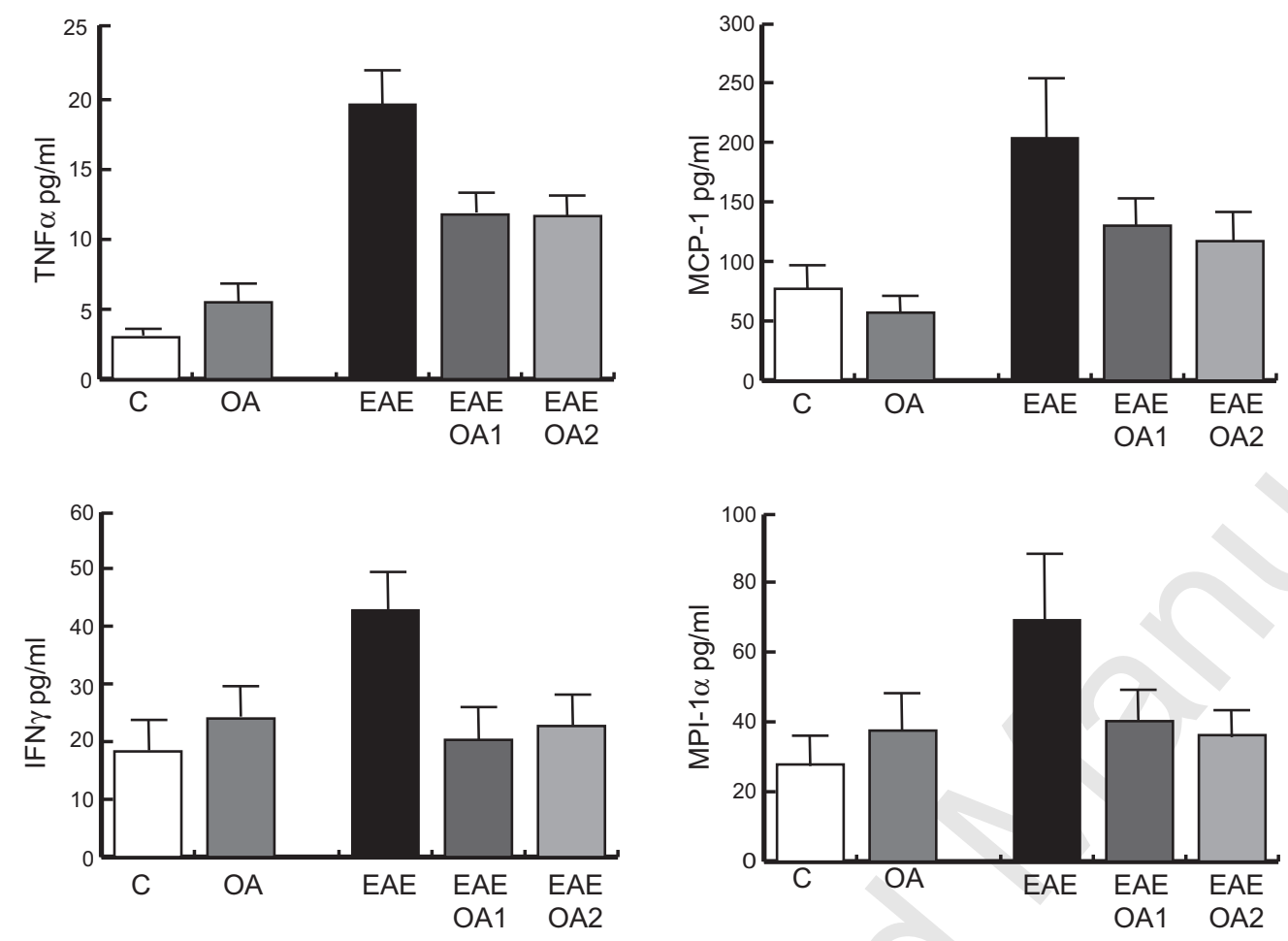

B
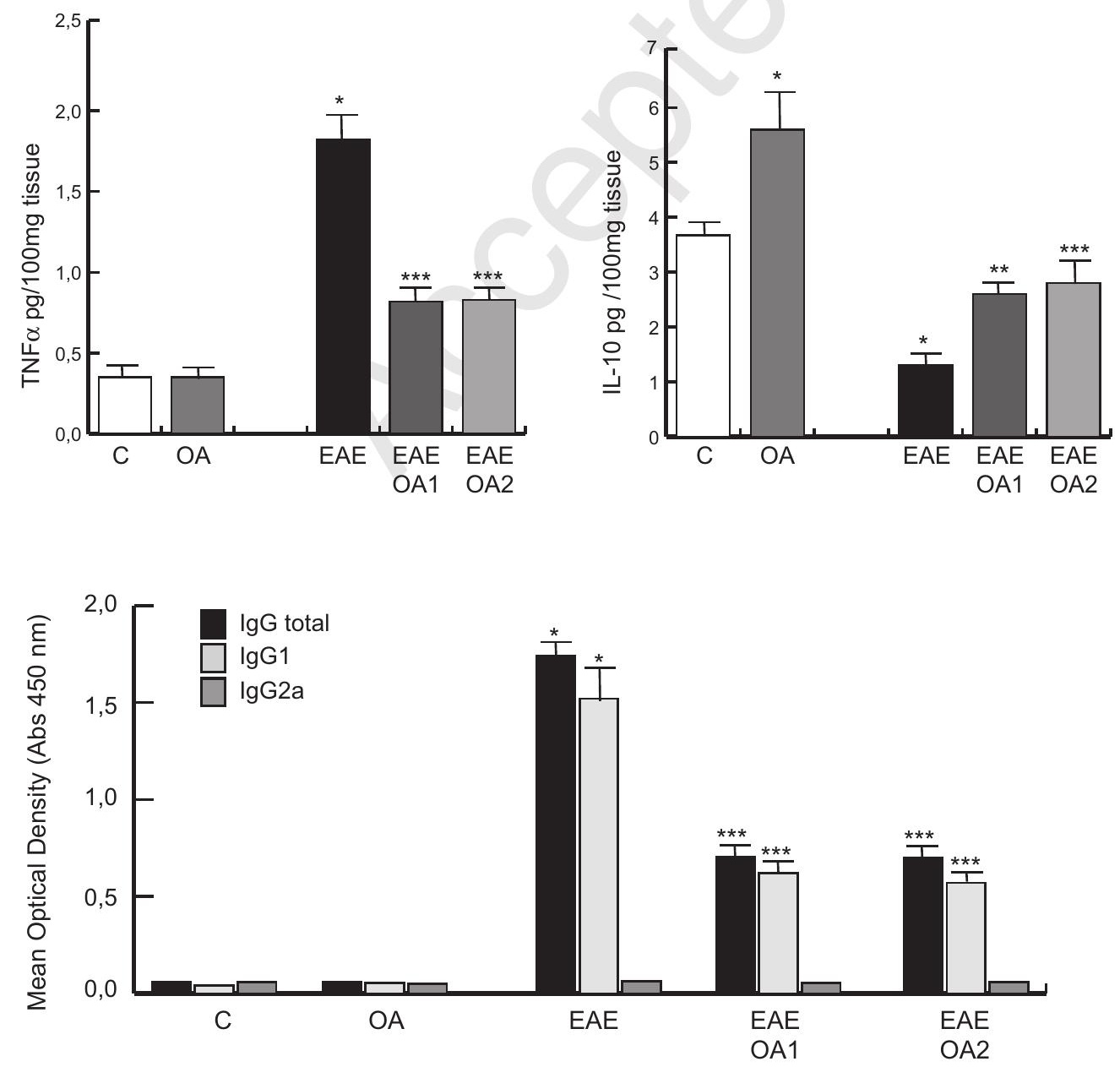


\section{Figure 7}

A
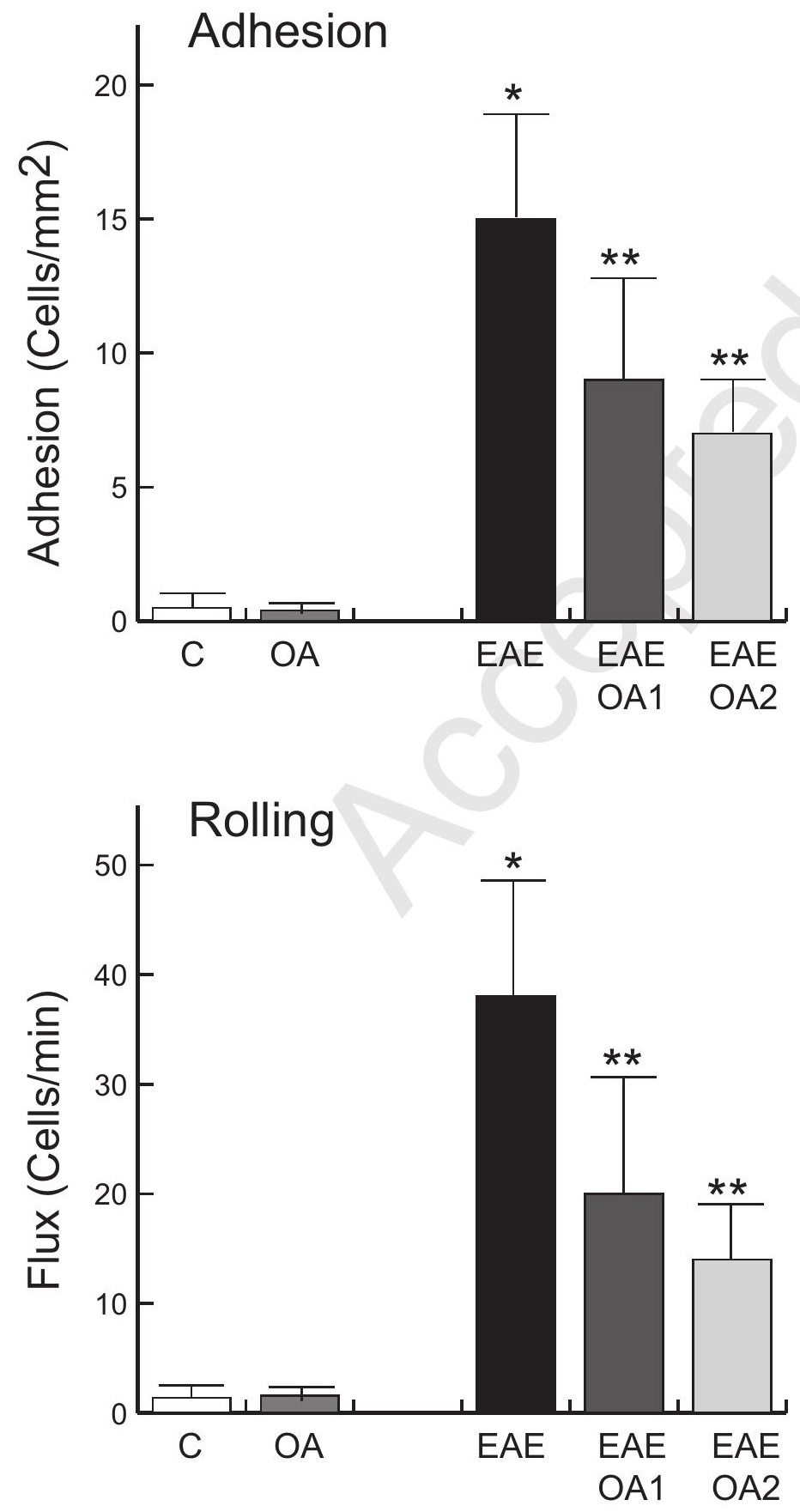
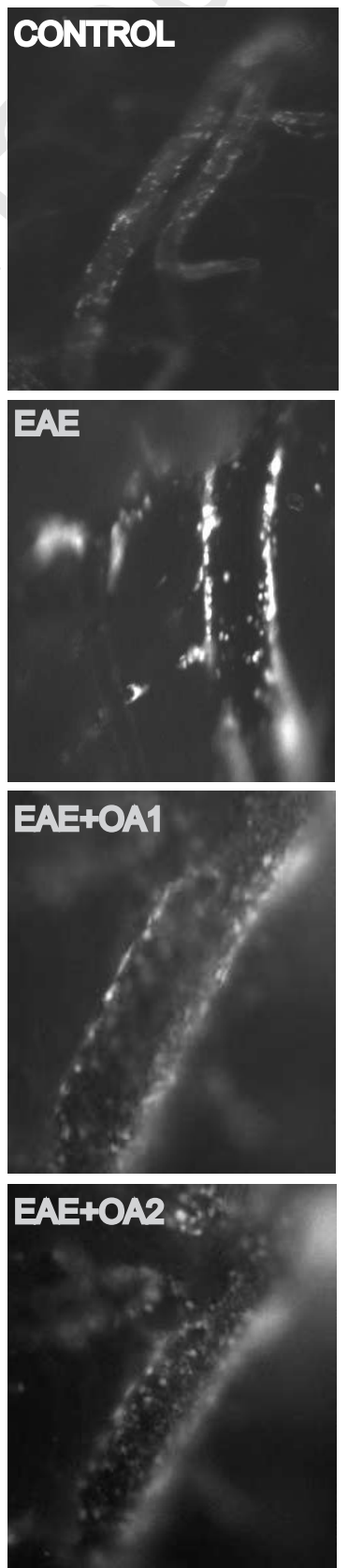

Page 41 of 43 


\section{Figure 8}

$A$
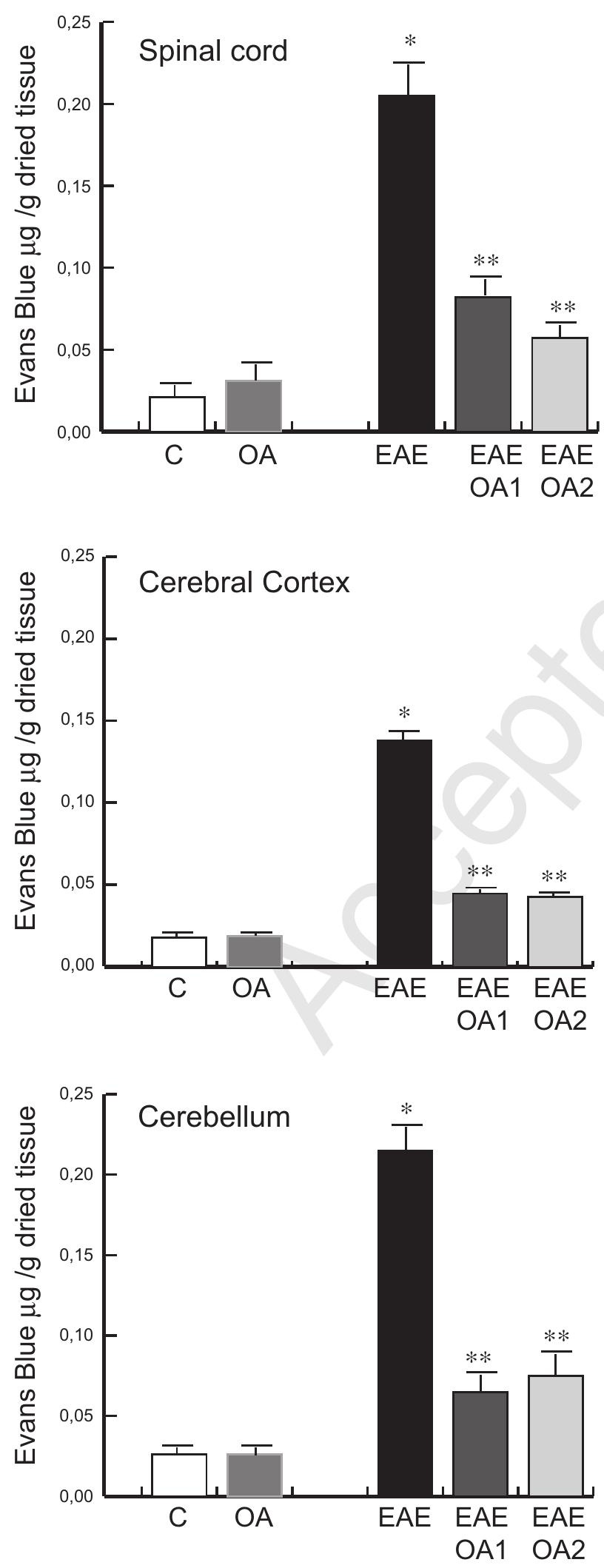
Semiprofilactic and therapeutic administration of the natural triterpene, oleanolic acid, can ameliorate the clinical signs of the experimental autoimmune encephalomyelitis.

A

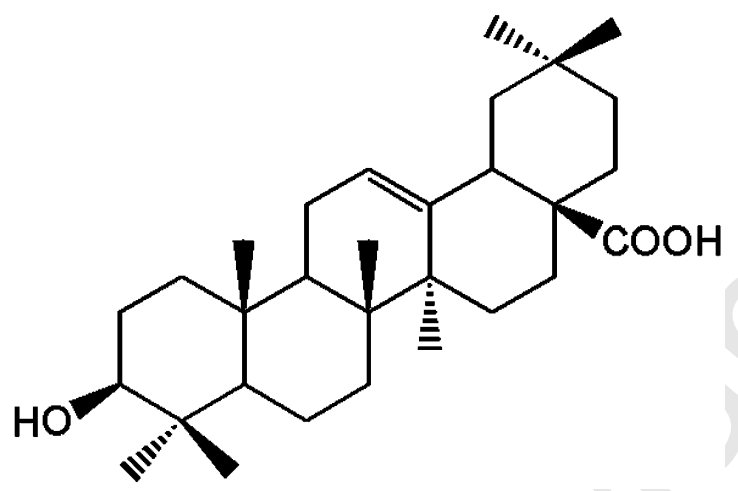

Molecular structure of Oleanolic Acid

B

OA1

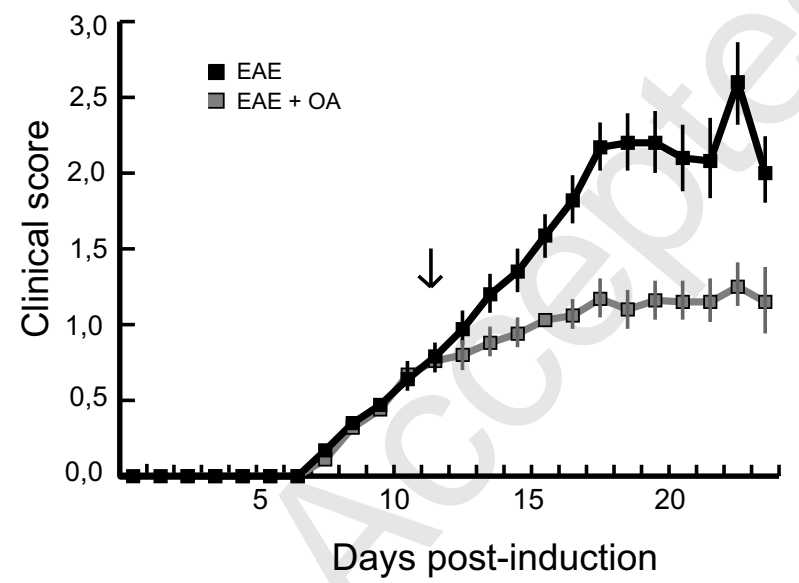

C

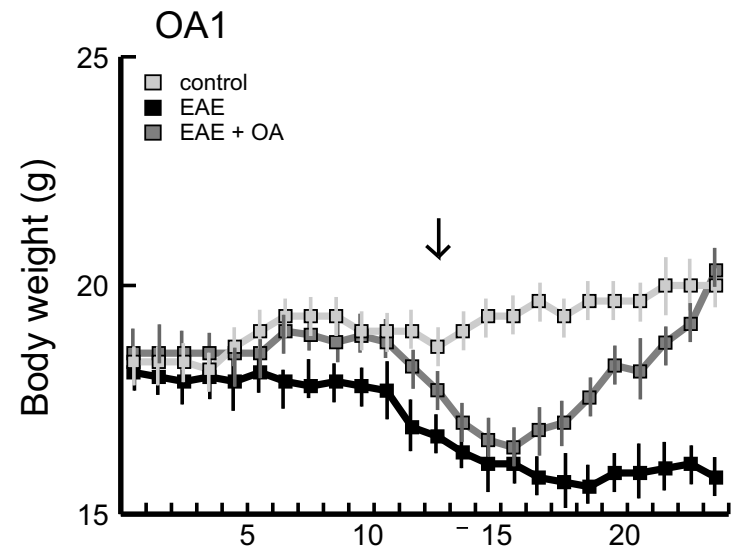

Days post-induction
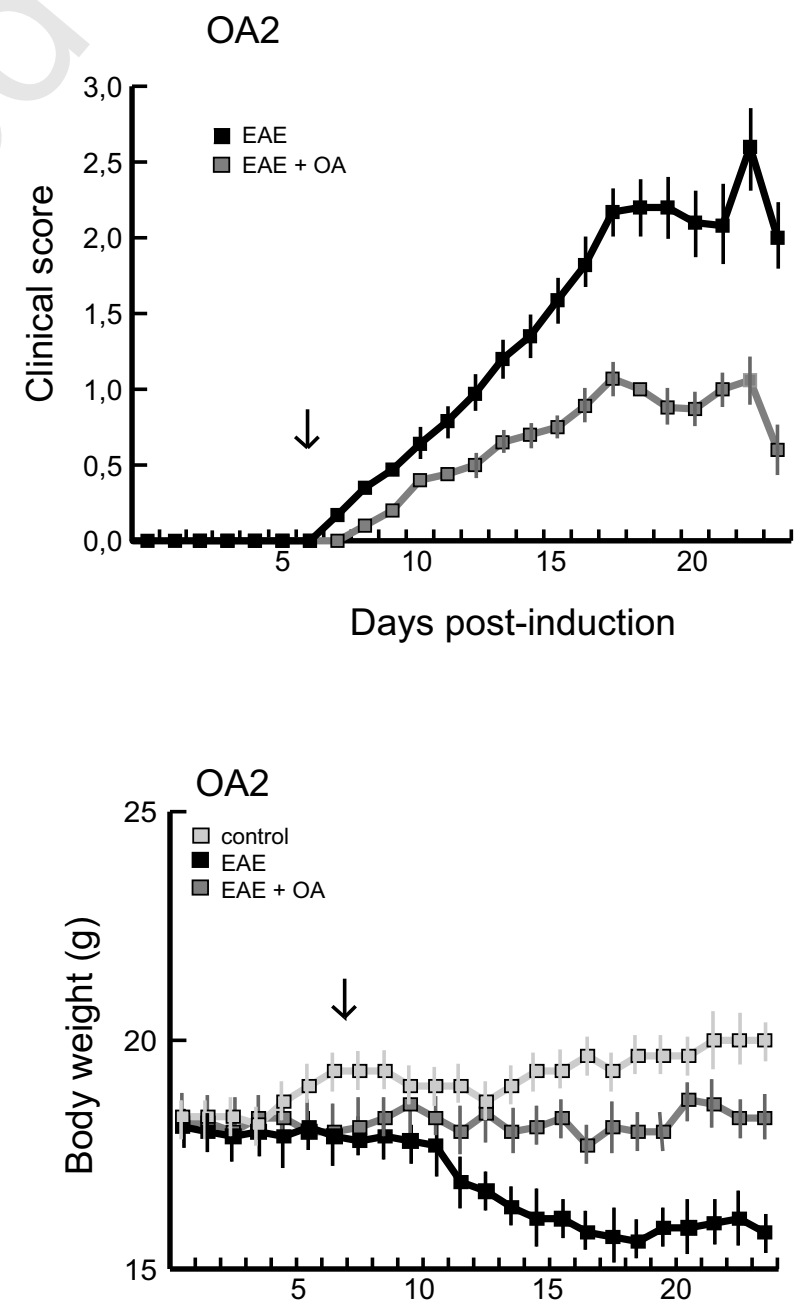

Page 43 of 43 